\title{
Wear and Friction properties of H-Al-17Si alloy with dry, lubrication and coated (DLC-Star) conditions under HFRR
}

\author{
N.D.Malleswararao.K ${ }^{1 *}$, Dr. I.N.Niranjan Kumar ${ }^{2}$, Dr. BH. Nagesh ${ }^{3}$ \\ ${ }^{1}$ ResearchScholar, Department of Marine Engineering, Andhra University, Visakhapatnam, A.P, India. \\ 2Professor, Department of Marine Engineering, Andhra University, Visakhapatnam, A.P, India \\ ${ }^{3}$ Adjunct Professor, Indian Maritime University, Visakhapatnam, Andhra Pradesh, India. \\ *Corresponding author: kndmrao@gmail.com
}

\begin{abstract}
Dry, lubrication (SAE15W40), and coated (DLC-Star) reciprocating tribological tests on rapid solidified AlSi17Cu3.5-4Mg0.6-0.8 alloy was conducted using a high frequency linear reciprocating rig (HFRR) at ambient temperature. The alloy fabricated with the rheo-stir squeeze casting procedure under T- 6 condition. However, at different loading $(0-30 \mathrm{~N})$ conditions, wear and friction properties of rapid solidified H-Al-17Si alloy are investigated. It is observed that the lower friction coefficient value obtained for DLC-Star coated H-Al-17Si alloy compared to dry and lubrication conditions. Though, for dry and lubricated sliding, the obtained wear coefficient values are 2.9X10-3 mm3 $/$ N.m and 4.0X10-4 mm33 N.m. A lower coefficient of wear value of $5.4 \times 10^{-5} \mathrm{~mm}^{3} / \mathrm{N} . \mathrm{m}$ was recorded with DLC-star coating under dry conditions. The alloy wear coefficient values first increases with applied load (up to $20 \mathrm{~N}$ ) and then decreases $(20 \mathrm{~N}$ to $30 \mathrm{~N}$ ). EDS, AFM surface roughness profilometer, SEM, and advanced metallurgical microscope (AMM) analysis techniques used for the characterization of surface morphologies. The developments in friction and wear coefficients were fundamentally ascribed to the dispersion and size of primary Si elements and the development of tribo-oxide films on the rapid solidified AlSi17 alloy coated (DLC-Star) surfaces.
\end{abstract}

Keywords: DLC-star coating, Friction, H-Al-17Si17 alloy, Lubrication, Wear

\section{Introduction}

Poor tribological characteristics of an alloy show higher emissions, more energy consumption, and a high rate of wear. So, it is certainly not only reduces the coefficient of friction but also improves the rate of wear of alloys used for the manufacturing of automobile parts. Moreover, wear and friction characteristics of mechanical components are complicated, being controlled by several factors, including surface structure, lubricants, distance, load, speed, and the contact shape [1]. However, scholars have evolved many tribological resolutions in terms of multi-grade lubricants, reduced weights of metal matrix composites (MMC), and advanced protective coatings to produce high-performance mechanical system components to improve efficiency, reduce emission, wear and friction losses [2-4]. Moreover, the demand for quality materials increased to produce high -performance engine components for withstanding extreme loads and temperature conditions [5-7].

In the last 20 years, hypereutectic Al-Si alloys (H-Al-Si $\mathrm{MMC}$ ) have been considered as a solution to enhance the performance of the mechanical engine components [8-9]. HAl-Si MMC possesses good resistance to wear, wonderful castability and excellent strength to weight ratio, that makes these MMC suitable for many friction and wear applications in mechanical engines, like cylinder liners, engine blocks, and pistons and in other various industrial applications [10-11]. H-Al-Si MMC are usually characterized as the composite where $\mathrm{Si}$ percentage is equal to or greater than $17 \mathrm{wt} \%$. Although, [12] the typical cast $\mathrm{H}-$ Al-Si MMC reached their limits of resisting heat and elevated temperature strength as the engine power increased. Accordingly, the researchers developed new casting techniques [13, 14] including spray deposition, powder metallurgy, and planar flow casting on rapid solidification to prepare high strength and high heat resistant H-Al-Si MMC. However, [12] these new techniques are challenging to execute, and the dimensions of the components are also finite. The use of ultrasonic vibration [15] during the stirring of H-Al-Si MMCs and squeeze is a comparatively latest process. It is a userfriendly technique with the benefits of low cost and simple operability [16-19].

The addition of Si like hard particles enhances the hardness, which in turn improves the alloys (H-Al-Si) wear -resisting properties [20, 21]. Vineet Tirth et al. and Khemraj et al. explored the impact of stir-squeeze casting on the wear and friction characteristics of hybrid aluminum matrix composite. They reported that the stir-squeeze 
Table 1 Al-17Si MMC Chemical composition

\begin{tabular}{lccccc}
\hline \multirow{2}{*}{ Alloy } & Fabrication Method & \multicolumn{4}{c}{ Chemical Composition (wt \%) } \\
\cline { 3 - 5 } & & $\mathrm{Si}$ & $\mathrm{Cu}$ & $\mathrm{Mg}$ & $\mathrm{Al}$ \\
\hline AlSi17 & Rheo stir squeeze casting (RSSC) & 17 & $3.5-4$ & $0.6-0.8$ & Balance \\
\hline
\end{tabular}

casting process substantially improved the hybrid composite [18-19, 22]. Dey et al. [23] executed tribological studies on Al-Si (18.5 wt\%) MMCs by varying load $0.5-5 \mathrm{~N}$ under the lubricated condition and found that few scratch marks are only left on the surface by Si particles, and alloy matrix was glued to the counterpart when the load increased. Clarke et al. explored [24] the wear behavior of Al-Si metal matrix composites (MMC = alloy) by changing Si weight percentage (up to $21 \mathrm{wt} \%$ ). They stated that the hyper eutectic MMCs have low wear resistance than hypoeutectic MMCs. However, Reddy et al. [25] carried out few coefficient of wear tests on a series of MMCs (AlSi), changing Si weight percentage to $23 \mathrm{wt} \%$ and addressing the reinforcement of hard primary $\mathrm{Si}$ particles alloy matrix enhances wear resistance of H-Al-Si MMCs. Coming after, Parveen Kumar et al. investigated the tribological behavior of AlSi25 MMC with different loading conditions $(5-100 \mathrm{~N})$ under lubricated and dry conditions using an LRT (linear reciprocating tribometer). In this research, it was noticed that with lubricating oil (SAE20W40) remarkable reduction in COF and wear coefficient is achieved [26]. Further, [27] the investigation continued by varying load 100-300 $\mathrm{N}$ and stated that at excessive loads, the MMC Si-particles were jutted out, then mix with lubricating oil and perform as a solid lubricant which results in substantial improvement in COF and wear rate.

Later many researchers examined the wear and friction characteristics of nanoparticles as engine oil (lubricant) additives. It has been noticed that the reinforcement of nano-granules into the engine oil (lubricating) improves the load-carrying capacity and reduces $\mathrm{COF}$ and wear rate [28-30]. However, at raised temperatures, large protuberances founded on the counterpart surfaces may increase wear and friction coefficients. To solve this problem, researchers tend to add fullerene (IF-Mos2 and h$\mathrm{BN})$ like nanoparticles into the lubricant liquids (SAE15W40), reported that the reinforcement of IF-Mos2 and h-BN nano granules into the lubricating oil enhances the anti-wear and friction properties remarkably [31-34]. From the above discussion, it is noticed that the reinforcement of Si grains into the metal matrix composite and reinforcement of nanoparticles into the lubricating oil improves the mechanical and tribological performance of automobile components.

Over the last few decades, one of the solutions for reducing wear and friction in automobile components is Diamond-Like Carbon (DLC) coating. DLC coatings show superior tribological characteristics [35-38]; Some studies [39-41] show that the hydrogenated-amorphous DLC layers $(\mathrm{a}-\mathrm{C}: \mathrm{H})$ are the promising wear and COF resistant coatings at different environmental conditions. Erdemir et al. reported that the hydrogen acts an essential function in determining the tribological characteristics of DLC films because of the preventing graphitization and promotes the formation of stabilized sp3 tetrahedral bonds [47-50]. However, DLC (a-C:H) coatings show excellent tribological properties for $\mathrm{Al}$ alloys at the ambient conditions of the other coatings like $\mathrm{CrN}$ and $\mathrm{TiN}$ [42-47]. Besides, few scholars [48-50] examined the behavior of DLC coatings on Al-alloys with inert gas and dry nitrogen environmental conditions and reported that the reduction in friction coefficient (0.001-003) is remarkable, and the wear rate (1010-10-11 $\mathrm{mm} 3 / \mathrm{Nm}$ ) was improved mainly. Later, researchers [51-52] conducted several research on a-C:H films at raised temperatures and described that the friction coefficient decreases, and the wear tracks become wide, bigger, and softer. From these studies, it is evident that the DLC coating has extraordinary potential as a hard film to combat $\mathrm{COF}$ and wear rate in different tribological uses.

It is explicit from the above studies that the wear and COF behavior of MMCs (H-Al-Si) rely upon on production routes and the silicon content [9, 20-21, and 53-57]. Besides, the experiments such as multi-grade lubricants, nano lubricants, and DLC coatings also much influence the wear and friction coefficients of the MMCs. The current research focuses on the impact of the casting process and coatings on wear and friction characteristics of hypereutectic aluminum-silicon MMC, which are popularly used in the production industry. The alloys have good potential for higher temperatures, hardness, and wear applications in production and automobile industries. Moreover, the use of DLC-Star coating with rheo stir squeeze casting H-Al-Si MMC has not been reported in published research. It is beneficial to apply the DLC-Star coating on H-Al-Si alloys

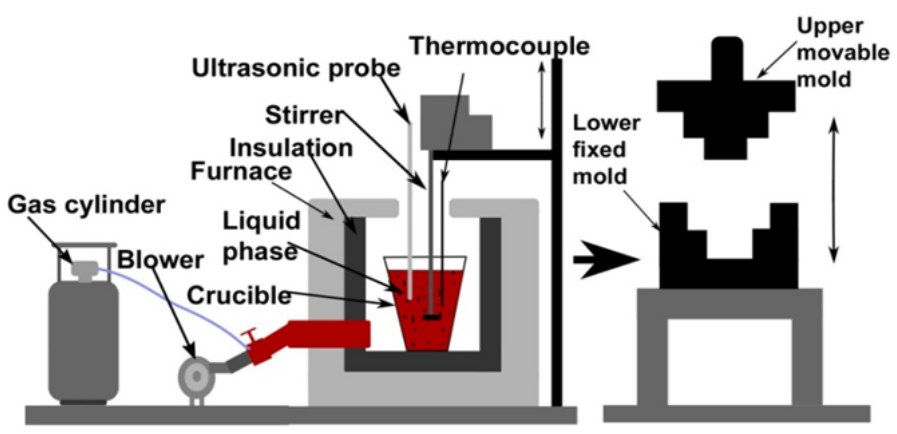

Ultrasonic vibration assisted stir casting Squeeze casting

Fig. 1 Rheo stir-squeeze casting process

Table 2 H-Al-17Si MMC EDS analysis

\begin{tabular}{cccccccc}
\hline \multirow{2}{*}{ S.no } & Alloy & \multicolumn{6}{c}{ Elements (wt \%) } \\
\cline { 3 - 8 } & & $\mathrm{Si}$ & $\mathrm{Cu}$ & $\mathrm{O}$ & $\mathrm{Mg}$ & $\mathrm{C}$ & $\mathrm{Al}$ \\
\hline 1 & AlSi17 & 15.98 & 3.61 & 1.12 & 0.47 & 4.99 & 73.83 \\
\hline
\end{tabular}


Table 3. H-Al-17Si MMC hardness values

\begin{tabular}{|c|c|c|c|}
\hline \multirow[t]{2}{*}{ Composition Load (kgf) } & Ball & Hardness value & Hardness value \\
\hline & $\begin{array}{r}\text { Diamet } \\
(\mathrm{mm})\end{array}$ & $\begin{array}{l}\text { efore heat treatme } \\
\qquad(\mathrm{BHN})\end{array}$ & $\begin{array}{l}\text { after heat treatment } \\
\qquad(\mathrm{BHN})\end{array}$ \\
\hline AlSi17 & 5 & 106.82 & 179.37 \\
\hline
\end{tabular}

Table 4 H-Al-17Si alloy Tensile characteristics

\begin{tabular}{ccccccc}
\hline \multirow{2}{*}{ Composition } & \multicolumn{2}{c}{ UTS } & \multicolumn{2}{c}{ YS } & \multicolumn{2}{c}{ Elongation (\%) } \\
\cline { 2 - 7 } & RSSC & RSSC-T6 & RSSC & RSSC-T6 & RSSC & RSSC-T6 \\
\hline AlSi17 & 261 & 386 & 235 & 312 & 2.1 & 0.8 \\
\hline
\end{tabular}

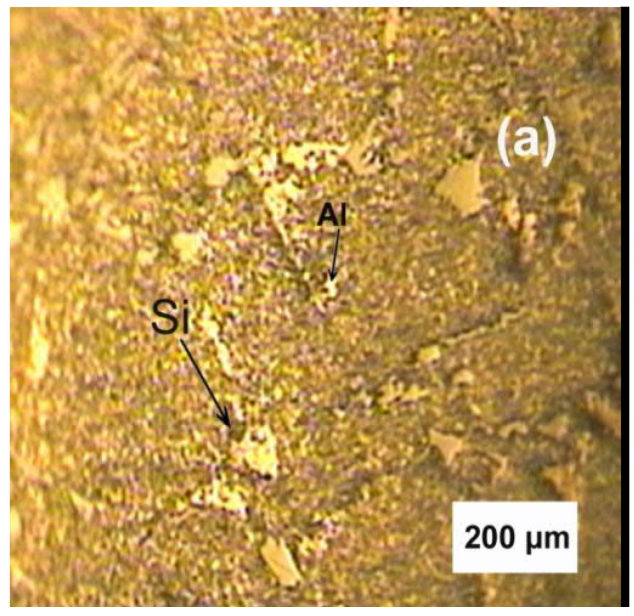

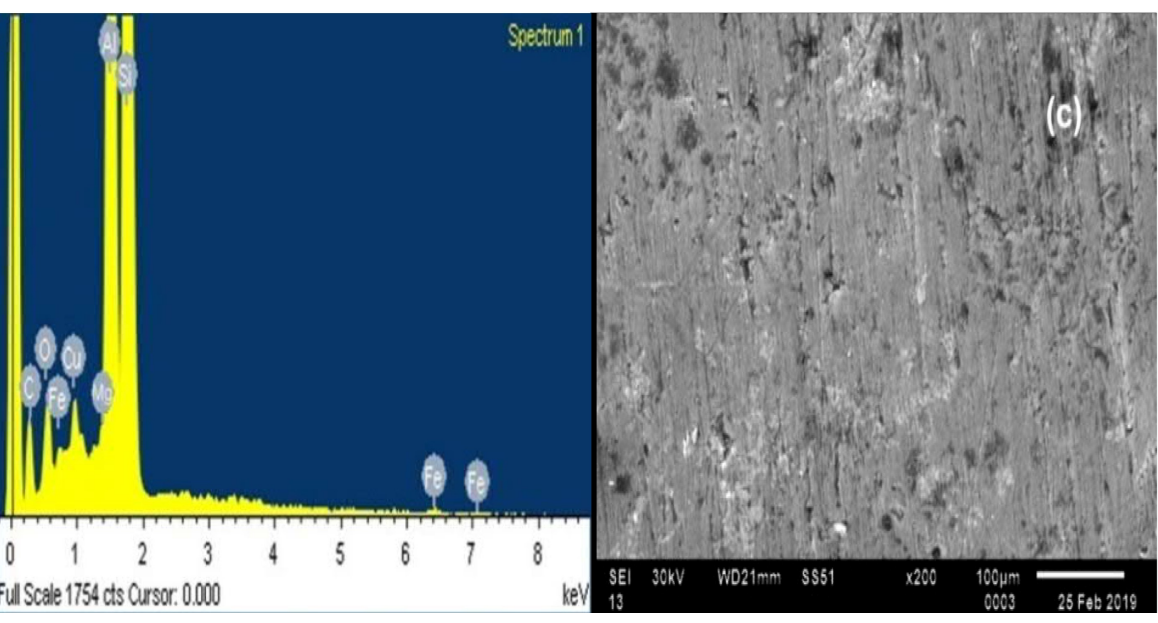

(b) EDS analysis, (c) SEM Microstructure for superior tribological properties. However, coatings identified for this study have been deposited by a combined PVD/PACVD method, which has been selected based on the literature review.

\section{Materials and methods}

\subsection{Materials and specimens preparation}

The hyper eutectic AlSi17Cu3.5-4Mg0.6-0.8 (H-Al-17Si) alloy was prepared by using rheo stir-squeeze (rheo = ultrasonic vibration (UV) assisted) casting technique under T-6 condition (RSSC-T6). However, the H-Al-17Si alloy (Table. 1) was processed with stir casting with UV treatment primarily and then carries on by squeeze casting procedure. The schematic diagram (Fig. 1) mainly consists of a furnace with stir casting setup, squeeze casting setup, UV generator, and titanium alloy horn. The used frequency for this UV test was $20 \mathrm{kHz}$, and the highest power output was $2.8 \mathrm{~kW}$.

The process begins with the melting of materials like pure $\mathrm{Al}$ and $\mathrm{Cu}$ in a gas furnace at $1100^{\circ} \mathrm{C}$. When the composite was completely liquified, then it was cooled to $720^{\circ} \mathrm{C}$ and stirred mechanically. Preheated silicon and magnesium $\left(270{ }^{\circ} \mathrm{C}\right)$ grains were added into the stir vortex around $15 \mathrm{~min}$ by keeping the speed of $300 \mathrm{rpm}$. The primary SiMg granules changed from coarse dendrites to regular polygons, and the average particle size decreased from 69.7 to $7.2 \mu \mathrm{m}$. Though, the compound was again heated to $650^{\circ} \mathrm{C}$, and UV was applied for about $5 \mathrm{~min}$. After mixing with UV completed, the alloy was poured into a mold of steel, which is already heated at $200^{\circ} \mathrm{C}$ temperature. A pressure of $200 \mathrm{MPa}$ was used in both directions (up and down) with a 60s holding time. Then the rapidly solidified square casting billet with 40X40X100 $\mathrm{mm}$ was achieved. Fig. 2 reveals the microstructure (optical and SEM) and chemical combination of H-Al-17Si alloy (EDS analysis: the used energy beam is typically in the range of $10-20 \mathrm{keV}$ ), and the elements weight percentages were indicated in Table.2. Further, the alloy (H-Al-17Si) was going through the heat-treatment operation with the $\mathrm{T}$ -6 environment. The T- 6 process consists of a solution heat treatment $\left(500^{\circ} \mathrm{C}\right)$ with a 4 hours drench time and then rapid quenching in $\left(<50^{\circ} \mathrm{C}\right)$ water later it was carried on with artificial aging at $165^{\circ} \mathrm{C}$ for 4 hours and then cooled in air. Square specimens of 40X40X10 mm were sliced out from the heat-treated billet. Whereas to understand the mechanical properties (Table $3 \& 4$ ) of H-Al-17Si alloys, the hardness (ASTM E10-15) (Fig. 3) and tensile properties (ASTM E8 / E8M) (Fig. 4) were investigated using Brinell hardness equipment and Tensometer.

\subsection{DLC-Star coating}

Oerlikon Balzers supplied the metal-free amorphous carbon (CrN+a-c: H) coating (Table 5) used in this 


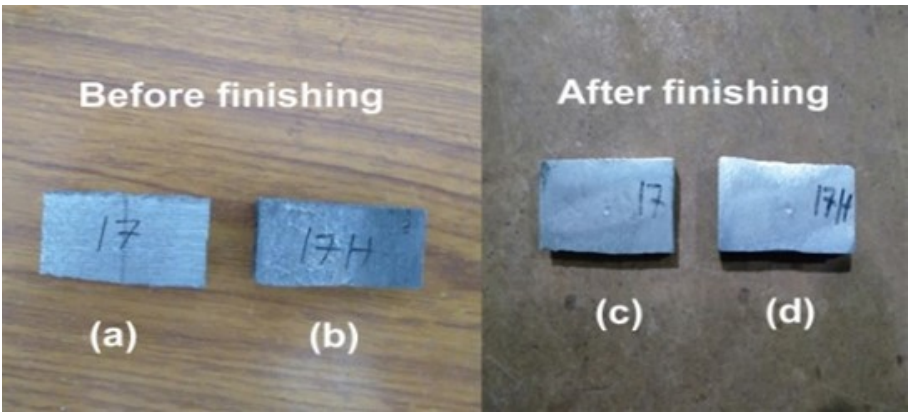

Fig. 3. Hardness test samples (a \& c) before heat treated, (b \& d) after heat treated,

\section{Turned tensile test piece}

\section{Dimensions are in B.S.}

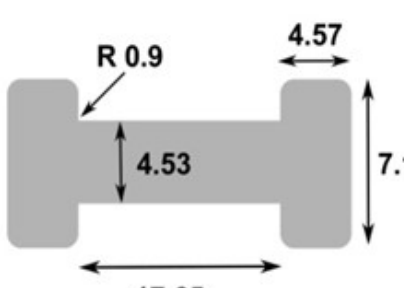

17.65

All dimensions are in $\mathrm{mm}$

Fig. 4. Tensile test samples

investigation. They were deposited by a combined PVD/ PACVD method on a square plate of H-Al-17Si alloy with 4 $\mu \mathrm{m}$ thickness. The coated surface was polished during the finishing process to remove the extra particles, and droplets maybe adhere to the top of the specimens (Fig. 5).

\subsection{Tribological tests description}

Wear and friction experiments were performed at room temperature using HFRR (High frequency linear reciprocating rig - ASTM G133) (Fig. 6) with a ball (10mm diameter) on a plate (square) geometry under dry, coated and lubricated conditions. All lubricated experiments are carried out with engine oil synthetic grade SAE15W40 as a lubricant (Table 6). The uncoated H-Al-17Si specimens (40X40X10 mm) surface preparation is done by polishing with Si-C papers (1000 and 800 grit size), and the surface final finishing is accomplished with diamond paste $(1 \mu \mathrm{m})$ After polishing, the specimens are cleaned with benzene and acetone to remove any detritus that may have been left while finishing. The applied load range during the friction and wear test was $5 \mathrm{~N}$ to $30 \mathrm{~N}$ at a $20 \mathrm{~Hz}$ frequency. The reciprocating experiment time was $10 \mathrm{~min}$ with a $2 \mathrm{~mm}$ stroke length and a sliding distance of $50 \mathrm{~m}$. AMM (VFM9100 Metzer Meta vision), AFM surface roughness profilometer (Veeco), and SEM (S-3700N) were used to study the microstructures of the alloys. After that, the friction coefficient values are directly obtained by the HFRR screen, and the $(\mathrm{Kw})$ wear coefficient of the alloys was determined with the following equation (1).

$$
\text { Wear coefficient }=\frac{\text { Wear volume }}{\text { (Applied Load X Sliding diatance })} \quad \frac{\mathrm{mm}^{3}}{\mathrm{~N} \cdot \mathrm{m}} \text {. }
$$

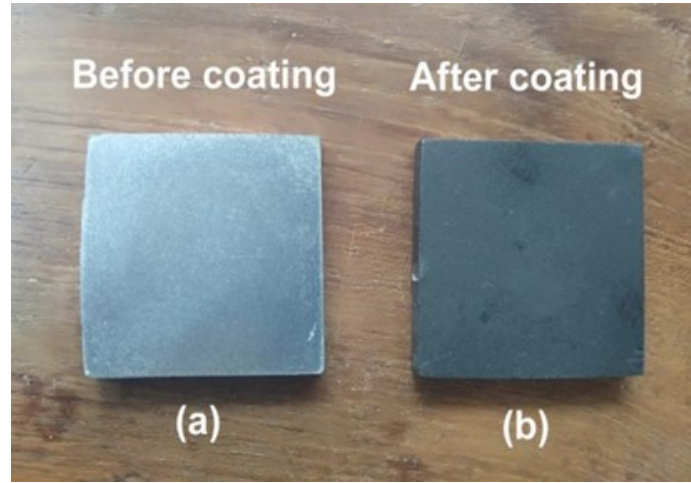

Fig. 5. H-Al-17Si samples (a) before coating, (b) after coating

Table 5 Properties of DLC-Star coating

\begin{tabular}{cc}
\hline Coating properties & Value \\
\hline Coating material & $\mathrm{CrN}+\mathrm{a}-\mathrm{C}: \mathrm{H}$ \\
Typical microhardness $(\mathrm{HK} 0.01)$ & $>2000$ \\
Typical coating thickness $(\mu \mathrm{m})$ & $2-4$ \\
Coating temperature $\left({ }^{\circ} \mathrm{C}\right)$ & $<250$ \\
Maximum service temperature $\left({ }^{\circ} \mathrm{C}\right)$ & 350 \\
Coating color & Black \\
\hline
\end{tabular}

Where wear volume is denoted as $W_{\mathrm{v}}\left(\mathrm{mm}^{3}\right)$, sliding distance is denoted as $S_{d}(m)$, and the applied load is denoted as $F_{n}(N)$.

\section{Results and discussion}

\subsection{Friction coefficient}

The friction coefficient and applied load values (mean value and standard deviation) are presented in Fig. 7. As shown in figure (Fig. 7) friction coefficient for H-Al-17Si MMC against AISI52100 ball in dry sliding condition initially recorded a high value $(0.78)$ then decrease with increase in applied load ( $5 \mathrm{~N}$ to $30 \mathrm{~N})$. However, a constant friction coefficient value of 0.064 , and 0.023 was obtained in the case of SAE15W40 lubricating oil and DLC-Star coating. It is evident from the above results (Fig. 7.) that the lowest friction coefficient value of 0.023 was achieved in the case of DLC-Star coating condition compared to dry (0.41) and lubricated (0.064) sliding conditions.

The friction coefficient of the H-Al-17Si MMC plate against AISI52100 ball under dry state decreases with increasing applied load ( $5 \mathrm{~N}$ to $30 \mathrm{~N}$ ) because of the presence of primary hard Si granules in the wear track of the H-Al-17Si MMC disc. However, the Si granules distribution and size play a significant role in reducing friction coefficient at increased applied loads. At the beginning of the experiment, the highest COF (Fig. 7) is recorded at $5 \mathrm{~N}$ load due to the $\mathrm{H}-\mathrm{Al}-17 \mathrm{Si} \mathrm{MMC}$ plate asperities that come into direct contact while sliding and stick to the AISI52100 ball surface which results in increased friction coefficient. Friction coefficient values are decreased with the increased applied load ( $10 \mathrm{~N}$ to $30 \mathrm{~N})$, as 
Table 6 SAE15W40 lubricating oil properties

\begin{tabular}{cc}
\hline Lubricant properties & Value \\
\hline Kinematic viscosity @ $100^{\circ} \mathrm{C}$, cSt & $14.0-15.2$ \\
Viscosity index & 130 \\
Flash point & $220^{\circ} \mathrm{C}$ \\
Pour point & $-21^{\circ} \mathrm{C}$ \\
\hline
\end{tabular}

represented in Fig. 7. This reduction in COF mainly attributed to the development of oxide-layers while sliding as the applied load increased. At higher applied loads, the hard Si granules jut out from the worn faces of $\mathrm{H}-\mathrm{Al}-17 \mathrm{Si}$ MMC disc and act as ball bearings at the contact surfaces during sliding.

In the case of SAE15W40 engine oil, the friction coefficient remarkably decreased. From Fig. 7, it is seen that the COF is decreased from 0.094 to 0.064 , with the increase of ( $5 \mathrm{~N}$ to $30 \mathrm{~N}$ ) applied load. It is because of the development of oil films between the tribopair. When the load increases, the friction coefficient decreases because of the hard Si particles of H-Al-17Si MMC mixes with engine oil (lubricant) and acts as a solid lubricant. The friction behavior of DLC-Star coated H-Al-17Si alloy is significantly improved compared to the lubricated and dry conditions. In the case of coated (DLC-Star) dry condition, the COF is significantly decreased (0.035 to 0.026$)$ with the increase in applied ( $5 \mathrm{~N}$ to $30 \mathrm{~N}$ ) load, as displayed in Fig. 7. Such a reduction in friction coefficient because of the highly absorbed $\mathrm{Si}$ grain improvement and the development of tribo-oxidation films between the mating parts. It is evident from the above values that the friction coefficient (Fig. 7) of H-Al-17Si MMC is greatly affected by the highly absorbed Si granules [58] and the coated materials. Additionally, the fabrication process of $\mathrm{H}-\mathrm{Al}-$ 17Si MMC [59] also contributed to achieving a decreased coefficient of friction results. Unique features of (DLC-Star) $\mathrm{CrN}+\mathrm{a}-\mathrm{c}: \mathrm{H}$ coating on the surface of the alloy resulted in the lowest friction coefficient in H-Al-17Si MMC, which

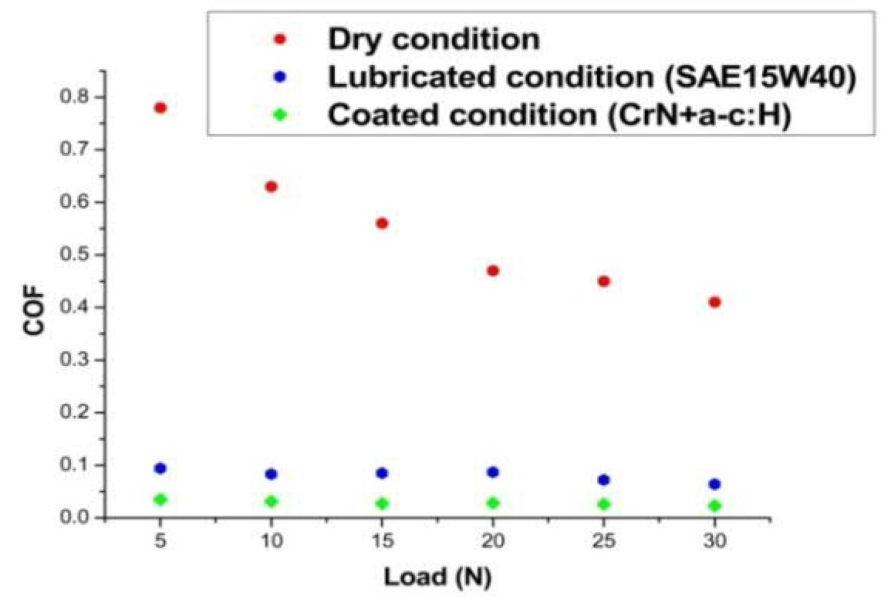

Fig. 7. Friction coefficient versus applied load for H-Al-17SI alloy

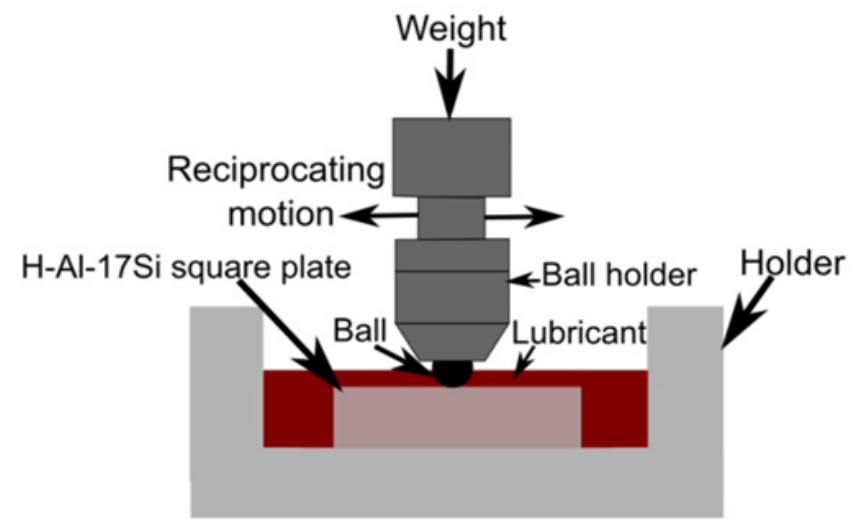

Fig. 6. HFRR setup

can strongly affect friction.

\subsection{Wear coefficient}

The $(\mathrm{Kw})$ coefficient of wear is driven by the ratio of Wv (wear volume) of MMC plate per Fn (applied load), per Sd (sliding distance). However, wear volume is estimated using the weight loss method where the alloy disc weight is calculated before and after the sliding experiments with an electronic balance. The wear coefficient (mean value and standard deviation) results procured for the H-Al-17Si MMC plate under dry, lubricated, and coated dry conditions are shown in Fig. 8. However, the wear behavior of H-Al-17Si MMC in the dry condition is split into two parts. In ( $5 \mathrm{~N}$ to $20 \mathrm{~N})$ part one, the wear coefficient of the H-Al-17Si MMC rose with the increase in applied pressure, and in part two $(20 \mathrm{~N}$ to 30 $\mathrm{N}$ ), the wear coefficient decreased. It can be observed that the highest wear coefficient value of $2.9 \times 10^{-3} \mathrm{~mm}^{3} / \mathrm{N} . \mathrm{m}$ was attained for $\mathrm{H}-\mathrm{Al}-17 \mathrm{Si}$ MMC under dry condition. Whereas, wear coefficient values of $4.0 \times 10^{-4} \mathrm{~mm}^{3} / \mathrm{N} . \mathrm{m}$ and $5.4 \times 10^{-5} \mathrm{~mm}^{3} / \mathrm{N} . \mathrm{m}$ are acquired for the H-Al-17Si MMC plate when (SAE15W40) lubricated and coated dry conditions accordingly. It is explicit from figure (Fig. 8) that the highest wear coefficient value of $2.9 \times 10^{-3} \mathrm{~mm}^{3}$ / N.m was attained under dry conditions, and the lowest

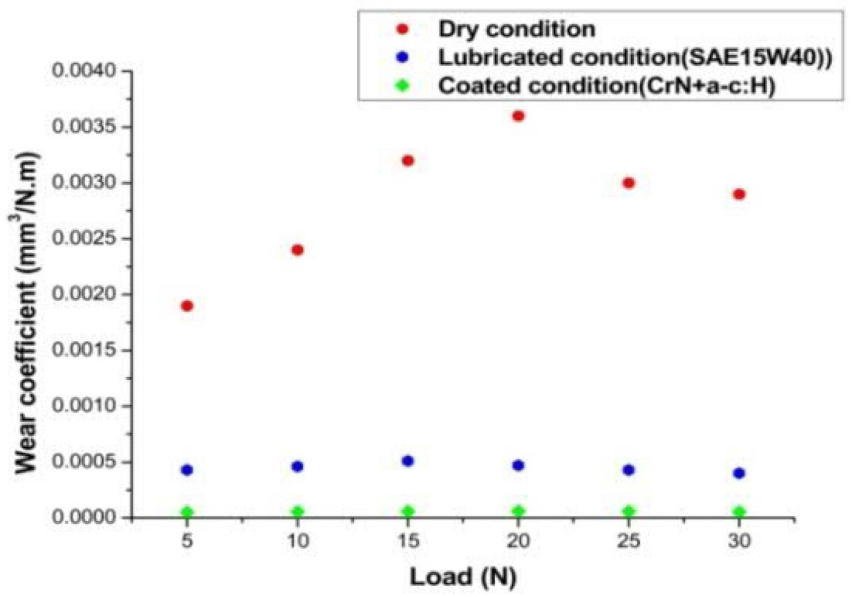

Fig. 8. Coefficient of wear versus applied load for H-Al-17Si alloy 

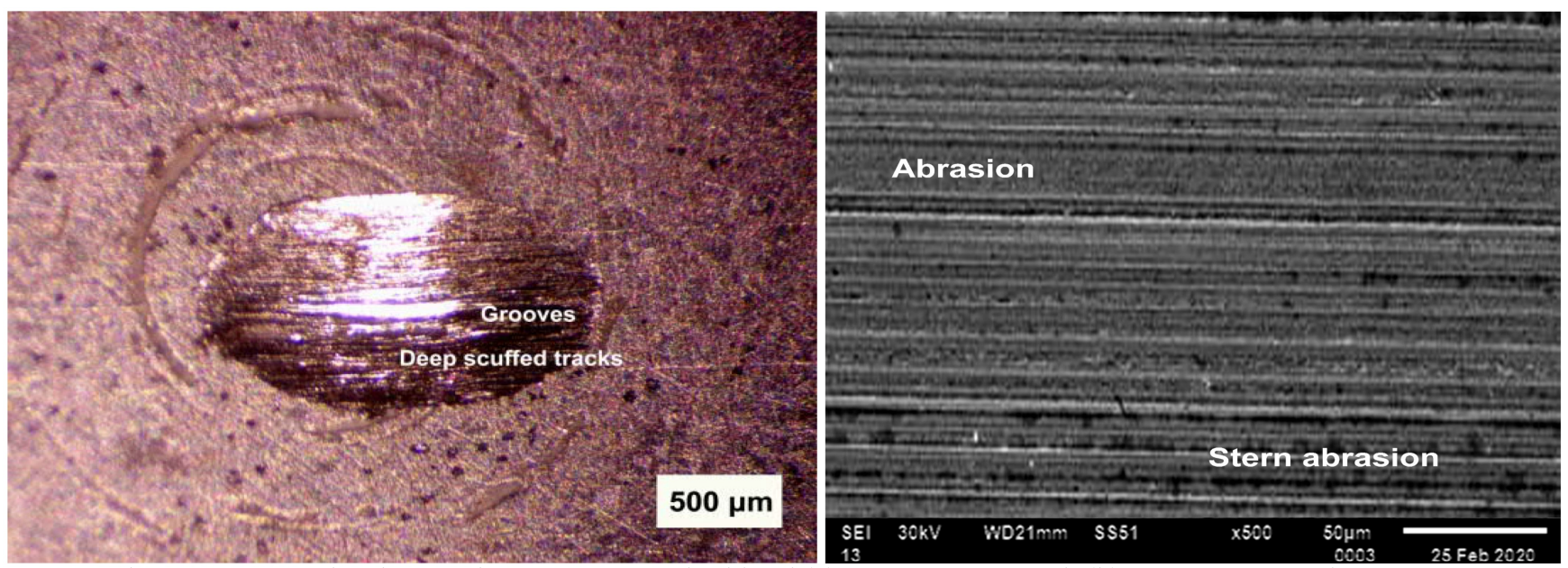

Fig. 9. H-Al-17Si MMC under dry condition at $5 \mathrm{~N}$ applied load (a) AMM micrograph (b) SEM micrograph
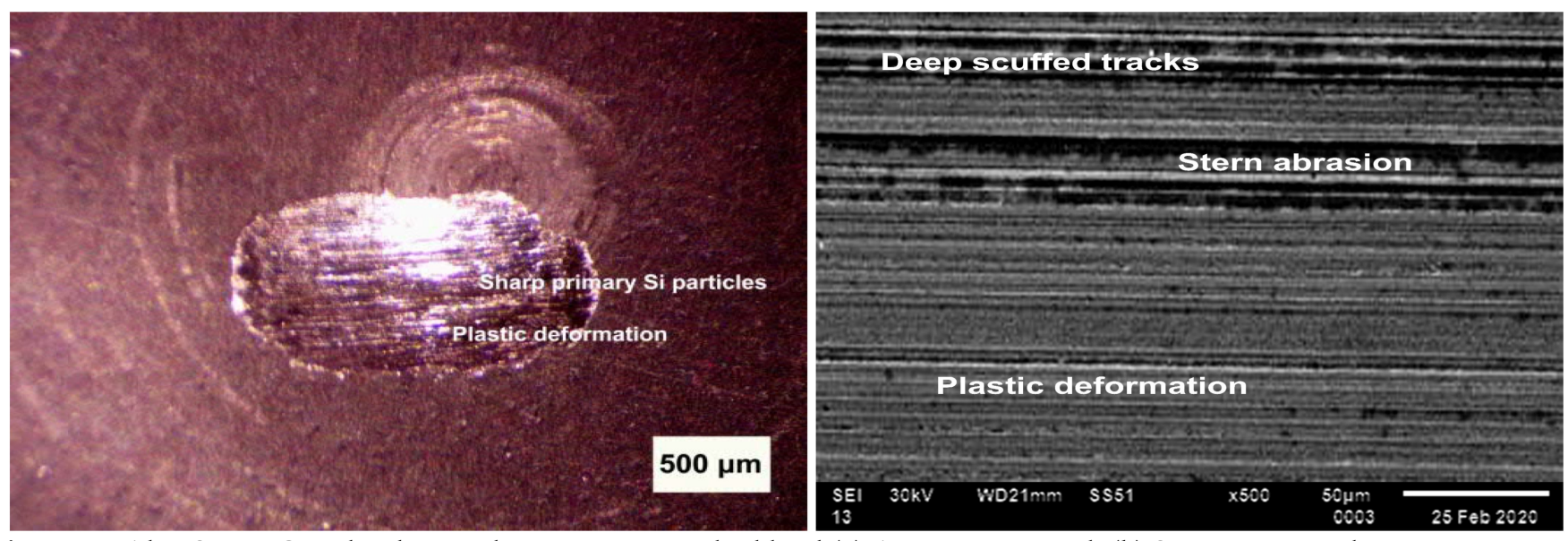

Fig. 10. H-Al-17Si MMC under dry condition at $20 \mathrm{~N}$ applied load (a) AMM micrograph (b) SEM micrograph
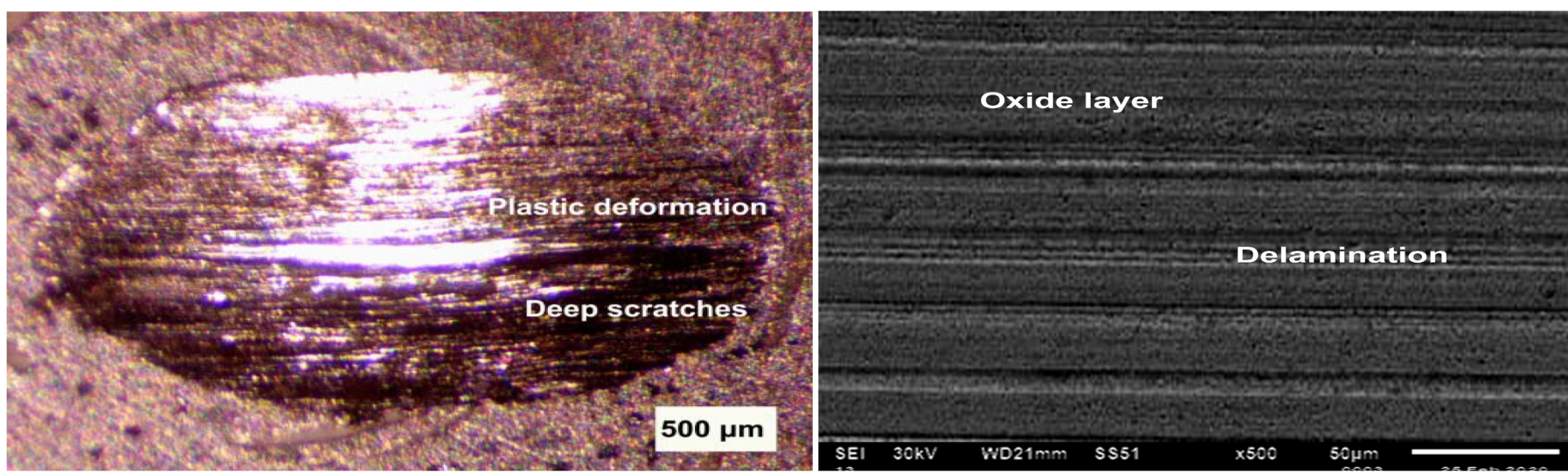

Fig. 11. H-Al-17Si MMC under dry condition at $30 \mathrm{~N}$ applied load (a) AMM micrograph (b) SEM micrograph

wear coefficient of $5.4 \times 10^{-5} \mathrm{~mm}^{3} / \mathrm{N} . \mathrm{m}$ was attained in case of coated (DLC-Star) dry conditions.

The wear coefficient of the MMC increases slowly with an increase in ( $5 \mathrm{~N}$ to $20 \mathrm{~N})$ applied load and decreases from $20 \mathrm{~N}$ to $30 \mathrm{~N}$, as shown in figure (Fig. 8). However, the $\mathrm{Si}$ granules distribution and size acts a significant function in deciding the wear coefficient of $\mathrm{H}-\mathrm{Al}-17 \mathrm{Si}$ MMC. At lower applied load, the adhesion between $\mathrm{H}-\mathrm{Al}-$ 17Si MMC plate and steel ball is occurred because of the high spots on H-Al-17Si disc surfaces that come into direct contact while sliding and stick to the AISI52100 ball surface. During constant sliding, the high spots are broken and result in adhesive wear, and the hard Si grains lead to surface abrasion. Optical and SEM (Fig. 9 \& 12) images of the worn surfaces of dry conditions show deep scuffed tracks, due to the association of abrasive and adhesive wear at 5N applied load. AFM profilometer (Fig. 27 (a)) images exhibit deformity on the MMC surface with a Ra value of $15.6 \mu \mathrm{m}$ at $5 \mathrm{~N}$ applied load. Figure (Fig. $10 \& 13$ ) shows that at applied load of $20 \mathrm{~N}$, the wear coefficient behavior of MMC remains unchanged because of the increase in abrasive and adhesive wear at high applied 


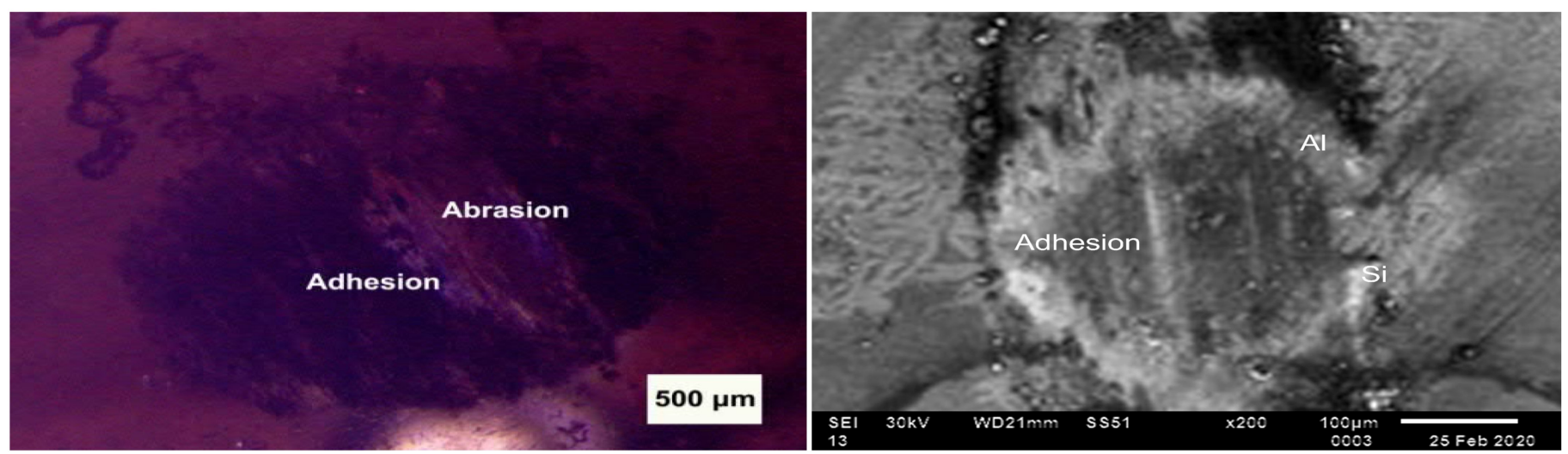

Fig. 12. AISI52100 Ball under dry condition at $5 \mathrm{~N}$ applied load (a) AMM micrograph (b) SEM micrograph

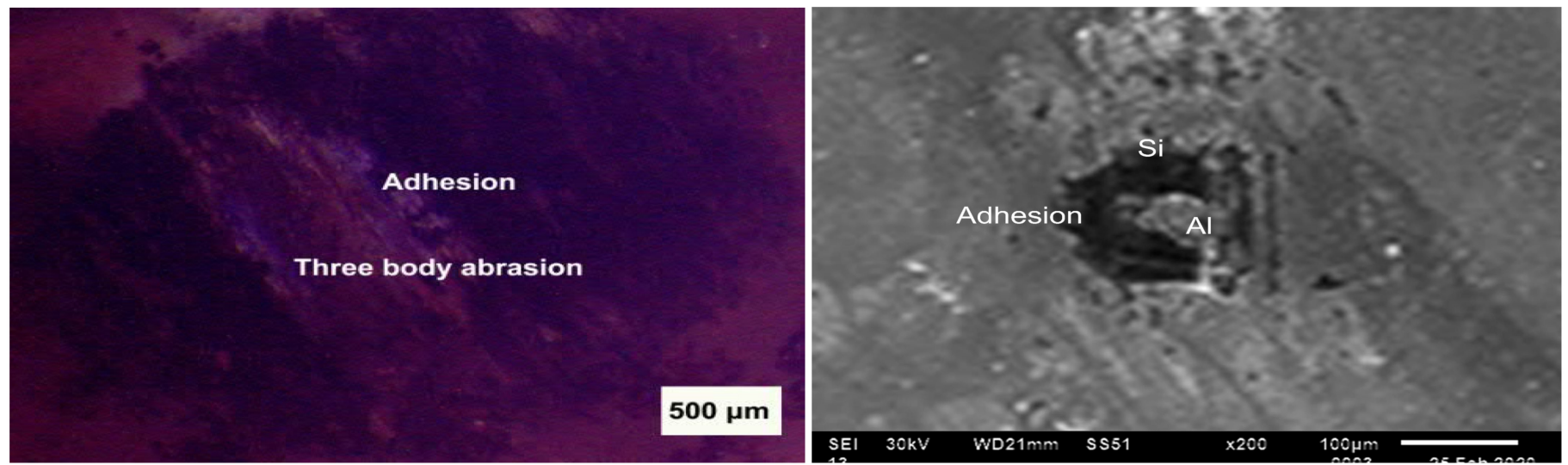

Fig. 13. AISI52100 Ball under dry condition at $20 \mathrm{~N}$ applied load (a) AMM micrograph (b) SEM micrograph
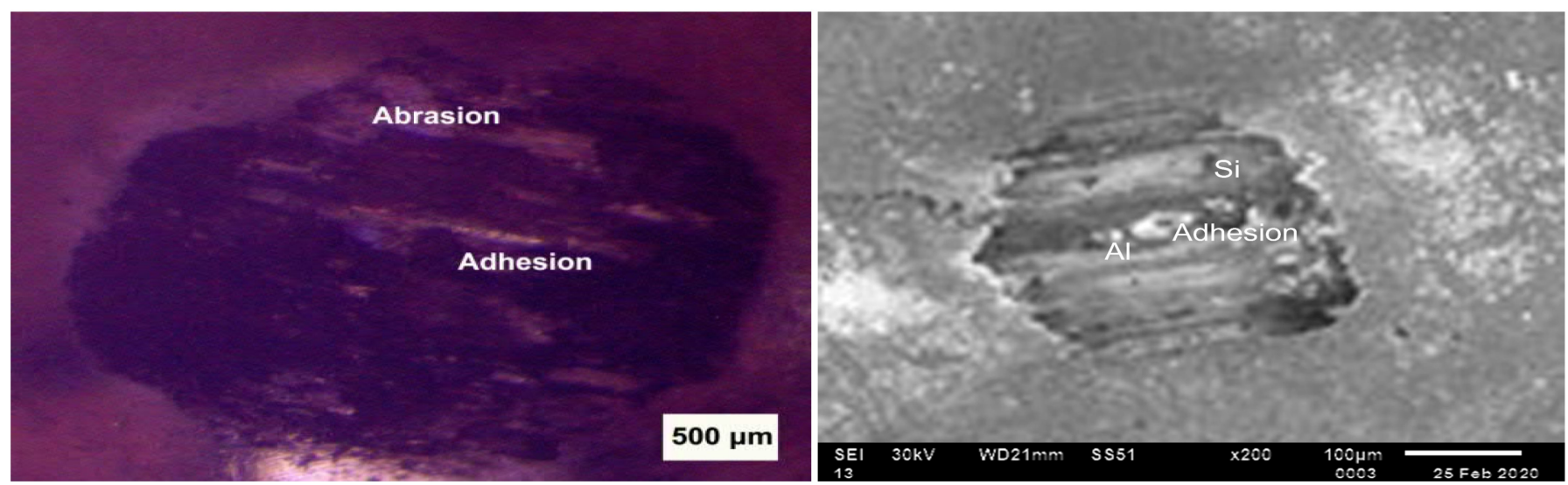

Fig. 14. AISI52100 Ball under dry condition at $30 \mathrm{~N}$ applied load (a) AMM micrograph (b) SEM micrograph

loads. AFM profilometer (Fig. 27 (b)) images also reveal the increased surface roughness $(\mathrm{Ra}=18.9 \mu \mathrm{m})$ value at $20 \mathrm{~N}$ applied load as compared to the $(5 \mathrm{~N})$ initial applied load. However, when the load further increased ( $20 \mathrm{~N}$ to $30 \mathrm{~N})$, the wear coefficient decreased due to the development of an oxide-layer between contact pairs

From figure (Fig. $11(\mathrm{a}, \mathrm{b})$ ), it is explicit that when the load increases, the abrasion level decreases due to the primary Si particles get distorted and a formed thin oxide layer. The developed oxide-layer acts as a solid lubricant between mating surfaces at more applied loads $(20 \mathrm{~N}$ to 30 $\mathrm{N})$ and reduces the wear coefficient. Further, optical and SEM images (Fig. 11 \& 14) confirm the development of the oxide layer and the existence of distorted Si granules on the wear tracks. Further AFM profilometer (Fig. 27 (c)) images of the wear track at applied load $30 \mathrm{~N}$ display a decrease in $(\mathrm{Ra}=9.6 \mu \mathrm{m})$ surface roughness value as compared to the surface roughness value $(\mathrm{Ra}=18.9 \mu \mathrm{m})$ at $20 \mathrm{~N}$ applied load. Though at higher applied loads due to the increase in temperature, a robust mechanical mixing layer formed and development of an oxide-layer occurs at the tribopair interface. Figure (Fig. 11 (b)) evident the existence of hard Si granules and development of the oxide -layer at the mating parts contact, which decreases the wear coefficient of the H-Al-17Si MMC. Further, at higher applied loads, elongated subsurface particles in the microstructure and work hardening layer strengthen the 


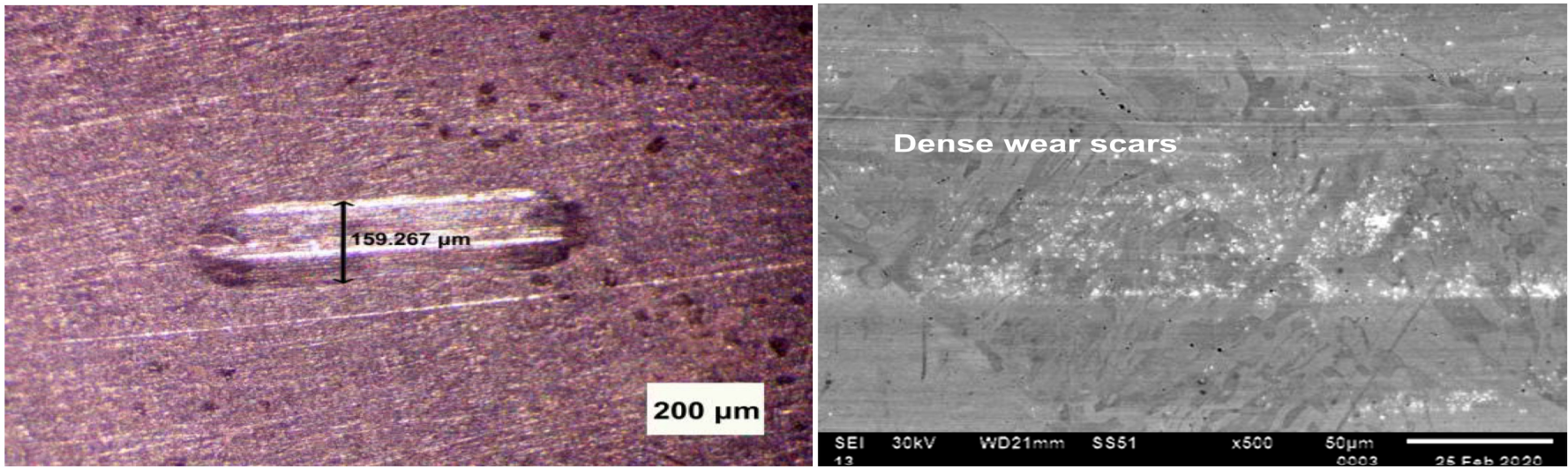

Fig. 15. H-Al-17Si alloy under lubricated condition at $5 \mathrm{~N}$ applied load (a) AMM micrograph (b)

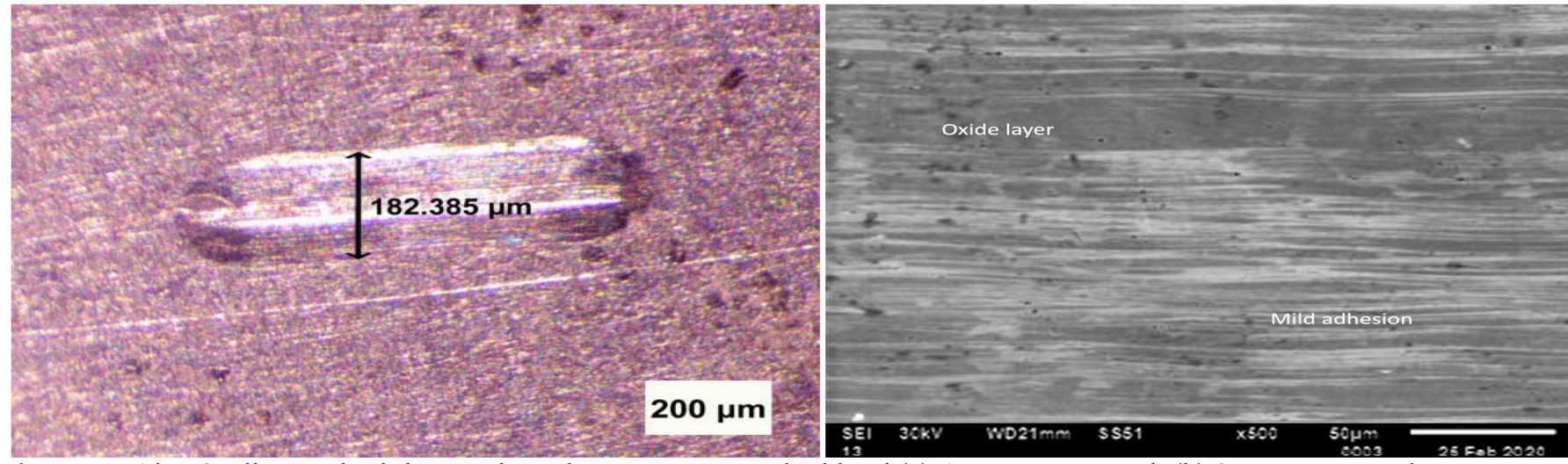

Fig. 16. H-Al-17Si alloy under lubricated condition at $20 \mathrm{~N}$ applied load (a) AMM micrograph (b) SEM micrograph
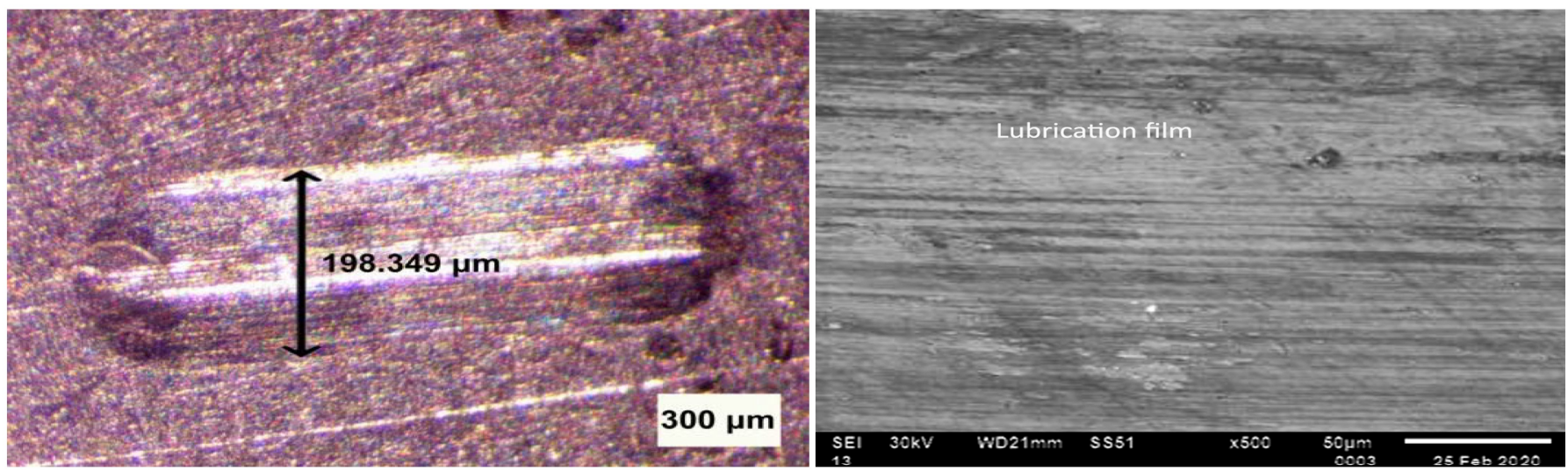

Fig. 17. H-Al-17Si alloy under lubricated condition at $30 \mathrm{~N}$ applied load (a) AMM micrograph (b) SEM micrograph

MMC surface because of the plastic deformation, enhancing the wear performance of $\mathrm{H}-\mathrm{Al}-17 \mathrm{Si} \mathrm{MMC}$. Additionally, the $\mathrm{Si}$ grains in the MMC also responsible for low friction and wear coefficients due to acting as a solid lubricant.

In the condition of lubrication with SAE15W40 oil, the wear coefficient was reduced extremely (Fig. 8). This is because of the development of oil film between tribopair, which avoids straight contact between mating surfaces. The formed oil film between H-Al-17Si MMC disc and AISI52100 ball reduces abrasion, adhesion, and plastic deformation remarkably, which decreases the in wear coefficient significantly. At lower (5 N) applied load, the wear tracks are very less, and one or two grooves with dense wear scars are present on the alloy surface (Fig. 15 \&
18). Whereas, at $20 \mathrm{~N}$ applied load, Fig. $16 \& 19$ shows light adhesion of asperities, which will marginally increase the wear coefficient of the H-Al-17Si disc. Further, profilometer images also clearly show the increased wear scars with an obtained roughness value of $\mathrm{Ra}=5.61 \mu \mathrm{m}$ (Fig. 28 (b)) as compared to the roughness value of $6.82 \mu \mathrm{m}$ (Fig. 28 (a)) at an applied load of 5 N. At $30 \mathrm{~N}$ applied load the coefficient of wear $(3.20 \mu \mathrm{m})$ (Fig. 28 (c)) again decreases compared to the $20 \mathrm{~N}$ applied load. This is due to Si granules mix with SAE15W40 lubricating oil and acts as solid lubricant and formation of smooth surfaces. Therefore, plastic deformation of asperities notably decreased because of the development of the lubricating layer (film) between tribopair, which decreases the wear coefficient of H-Al-17Si MMC. The Optical and SEM 


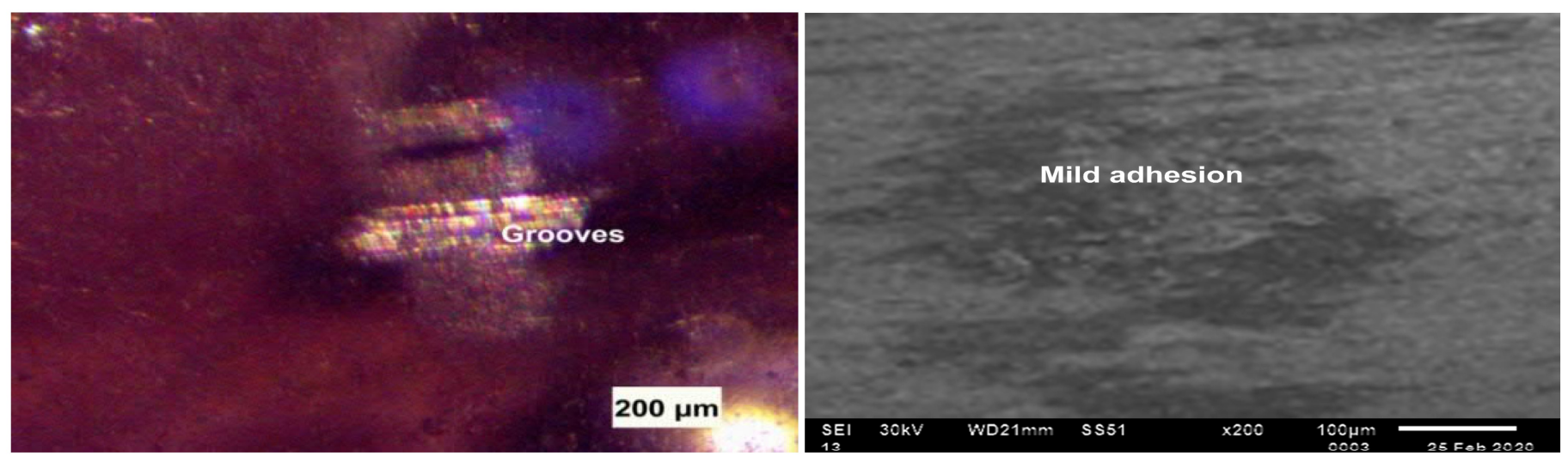

Fig. 18. AISI52100 ball under lubricated condition at $5 \mathrm{~N}$ applied load (a) AMM micrograph (b) SEM micrograph

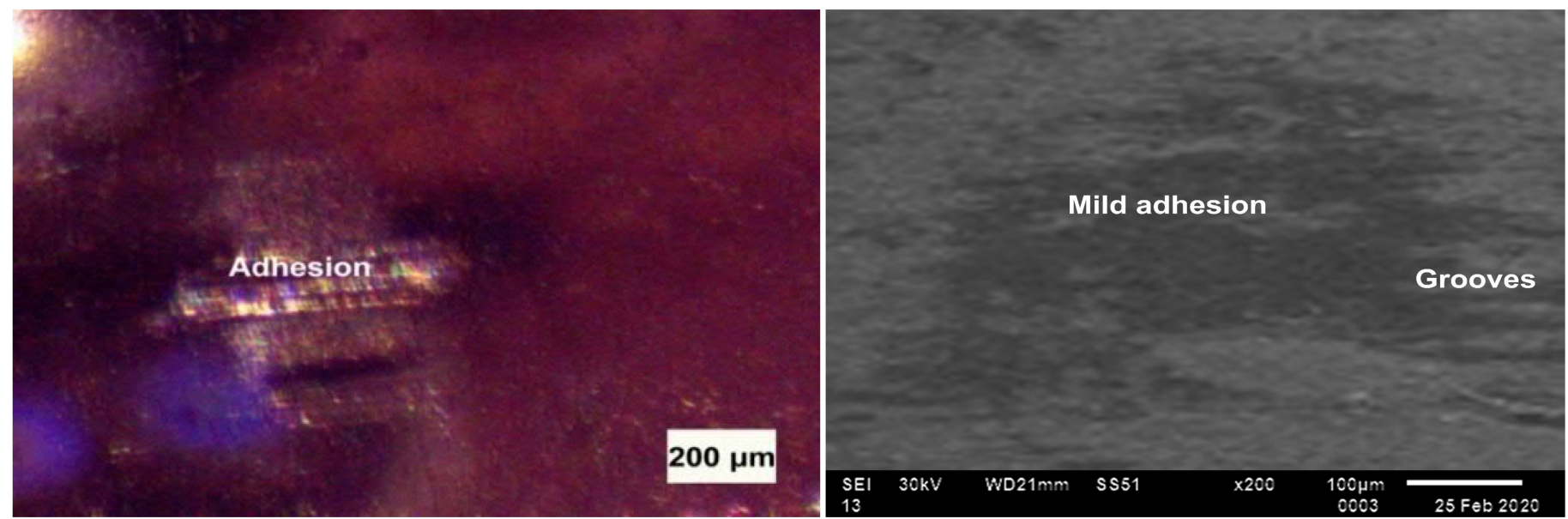

Fig. 19. AISI52100 ball under lubricated condition at $20 \mathrm{~N}$ applied load (a) AMM micrograph (b) SEM micrograph

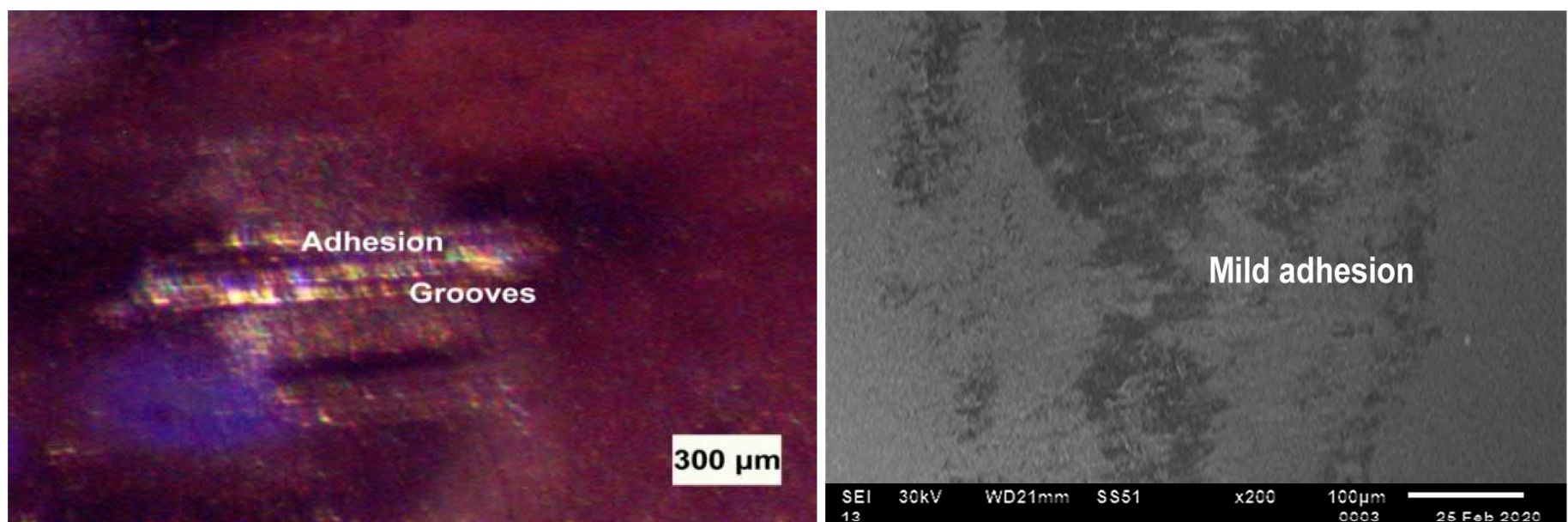

Fig. 20. AISI52100 ball under lubricated condition at $30 \mathrm{~N}$ applied load (a) AMM micrograph (b) SEM micrograph

images (Fig. 17 \& 20) show the surface remains smoother at higher applied load (30 N). Moreover, AFM profilometer images also evident the decreased wear scars value of $\mathrm{Ra}=3.20 \mu \mathrm{m}$ (Fig. 28 (c)) at $30 \mathrm{~N}$ applied load compared to the $20 \mathrm{~N}$ load $(\mathrm{Ra}=6.82 \mu \mathrm{m})$ (Fig. $28(\mathrm{a})$ ).

However, in case coated dry condition, the wear coefficient was reduced significantly as compared to both lubricated and dry conditions (Fig. 8). As shown in Fig. 21 \& 24, the wear tracks of H-Al-17Si with DLC-Star coating appear smoother and smaller. This is due to the development of a tribo oxidation layer (A tribo oxidation layer is usually developed on the mating surfaces at high temperature friction and wears process, which greatly affects the wear and friction properties of the alloys), which avoids the tribo pairs from coming into straight contact and remarkably improves the wear coefficient behavior of the MMC. At $5 \mathrm{~N}$ lowest applied load, the wear coefficient is nearly negligible due to the higher surface finish of DLC-Star coating. However, with the increasing of applied load $(20 \mathrm{~N})$, very thin smaller, and smoother wear scars appear on the surface of the alloy (Fig. $22 \& 25$ ) with the increased wear coefficient. Further, as the load $(30 \mathrm{~N})$ increases, the coefficient of wear again 

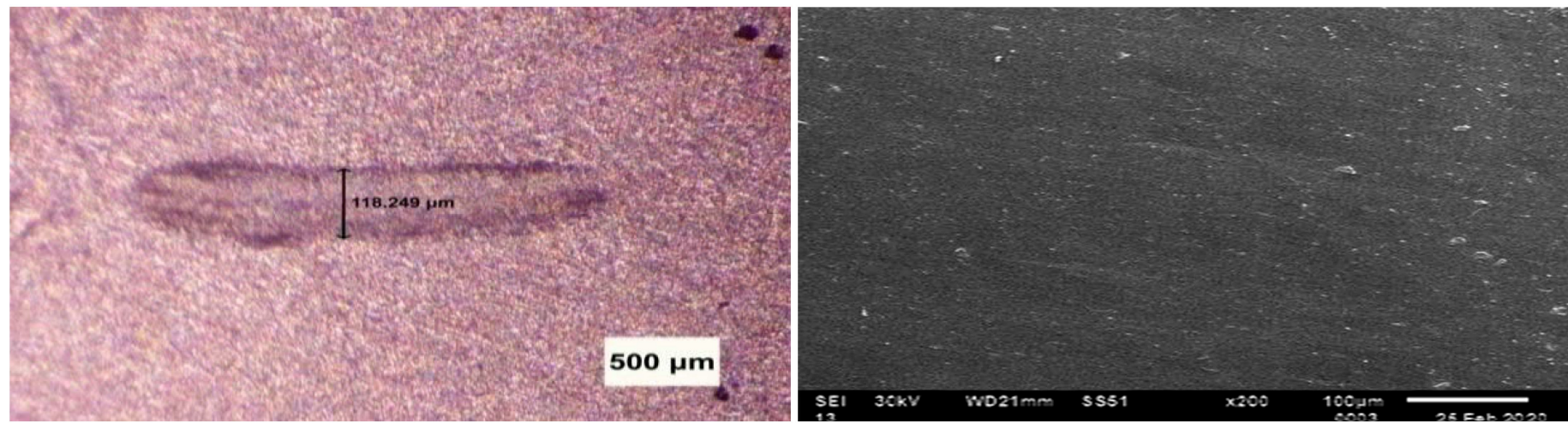

Fig. 21. H-Al-17Si alloy under coated dry condition at $5 \mathrm{~N}$ applied load (a) AMM micrograph (b) SEM micrograph
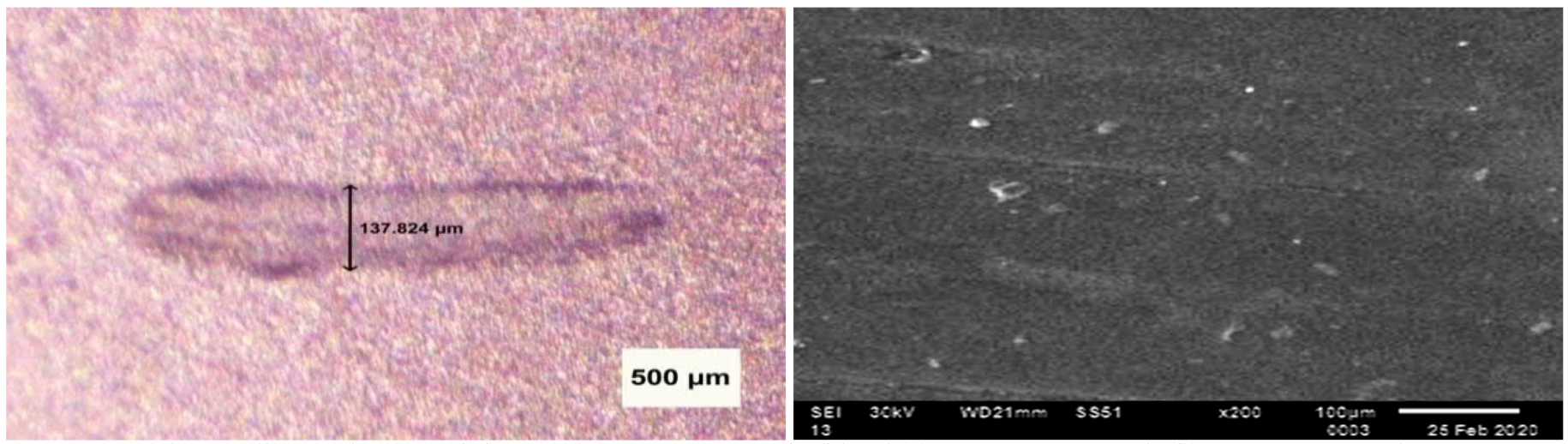

Fig. 22. H-Al-17Si alloy under coated dry condition at $20 \mathrm{~N}$ applied load (a) AMM micrograph (b) SEM micrograph
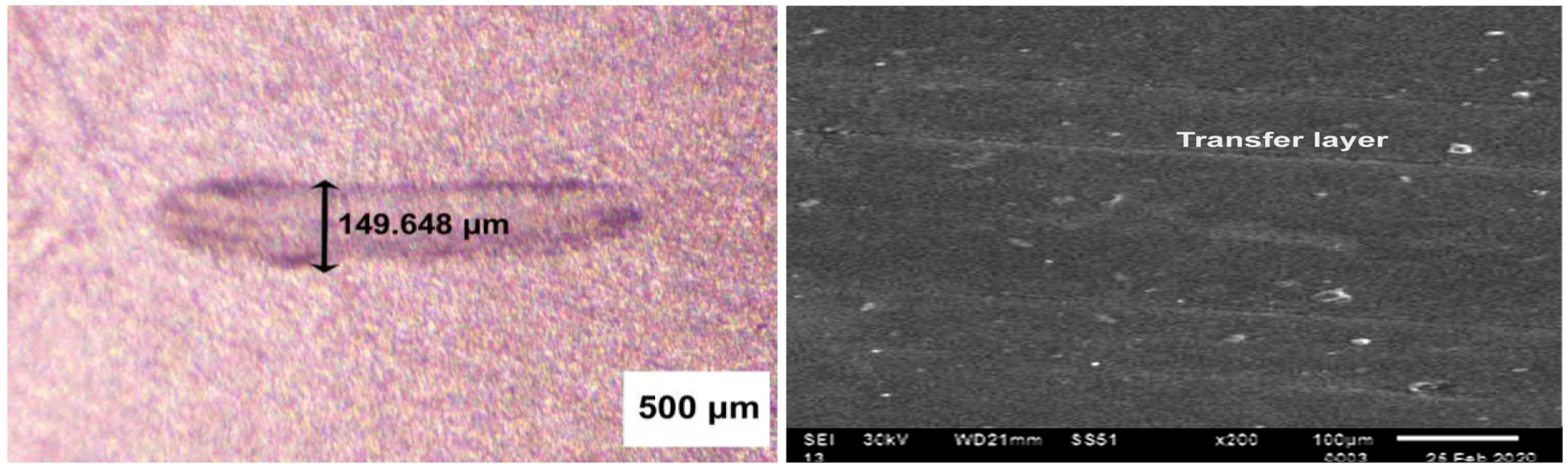

Fig. 23. H-Al-17Si alloy under coated dry condition at $30 \mathrm{~N}$ applied load (a) AMM micrograph (b) SEM micrograph

decreases (Fig. 23 \& 26) due to the development of a tribo oxidation film between tribo pair surfaces. The wear scar width in the coated dry condition (Fig. 23) is two times smaller than that of the wear scar (Fig. 17) attained in lubricated condition. Whereas, insignificant wear scars are identified on the AISI52100 ball in case of the coated dry condition (Fig. 24 - 26), which is ascribed to the improved wear resistance of steel ball because of its more hardness (670-770 HV) value as compared to H-Al-17Si MMC disc hardness (165-179.37 HV). Fig. 29 represents AFM profilometer images of the wear scars of H-Al-17Si MMC disc undercoated dry condition. As shown in Fig. 29 (a - c), surface roughness value decreased with increased applied load $(5 \mathrm{~N}$ to $30 \mathrm{~N})$. The surface roughness value decreased from $0.294 \mu \mathrm{m}$ (applied load $20 \mathrm{~N}$ ) to 0.134 (applied load $30 \mathrm{~N})$. The obtained values show that the alloy disc wear scars' surface roughness especially decreases with lubricated and coated dry conditions, while smoother surfaces were obtained with DLC-Star coating. However, the high wear coefficient occurs in the dry state when no protective film presents on the MMC surface (width of the wear mark is $840 \mu \mathrm{m})$.

It is implicit from these values that DLC-Star coating reduced the wear coefficient of about $30-50 \%$ compared to dry condition. The COF for DLC-Star for H-Al-17Si MMC is the minimum (0.023) throughout the experimental processes as compared to both lubricated and dry environments. The developments in friction and wear coefficients were primarily ascribed to the distribution and size of primary Si granules (Fig. 2(a)) and the formation of transfer layers on the coated surfaces of AlSi17Cu3.5$4 \mathrm{Mg} 0.6-0.8$ alloy (Fig. 23(b)). The anti-wear characteristic of 


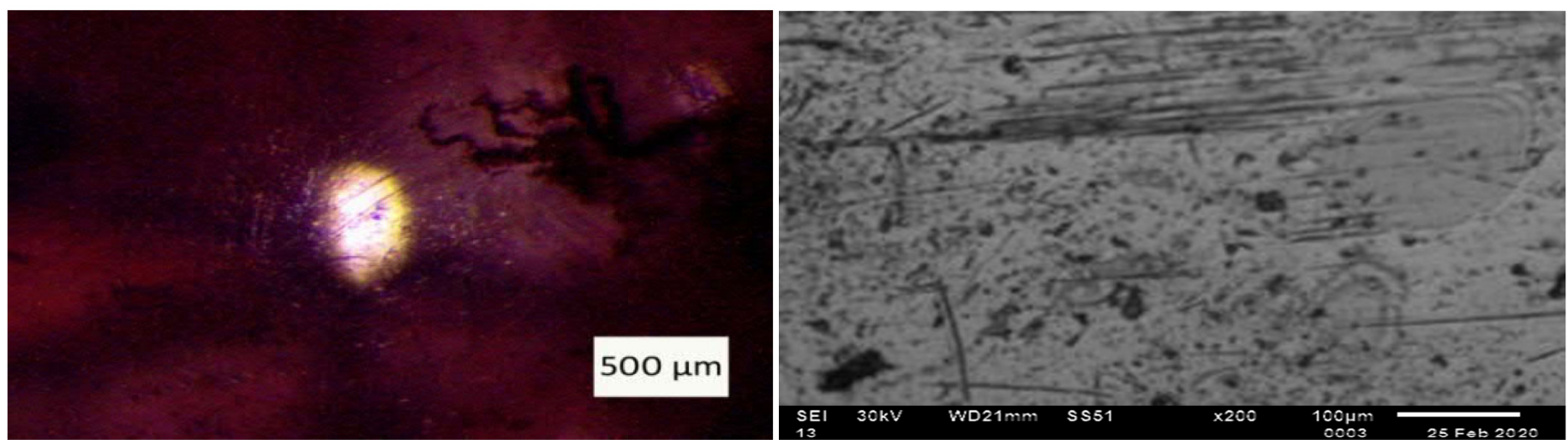

Fig. 24. AISI52100 ball under coated dry condition at $5 \mathrm{~N}$ applied load (a) AMM micrograph (b) SEM micrograph

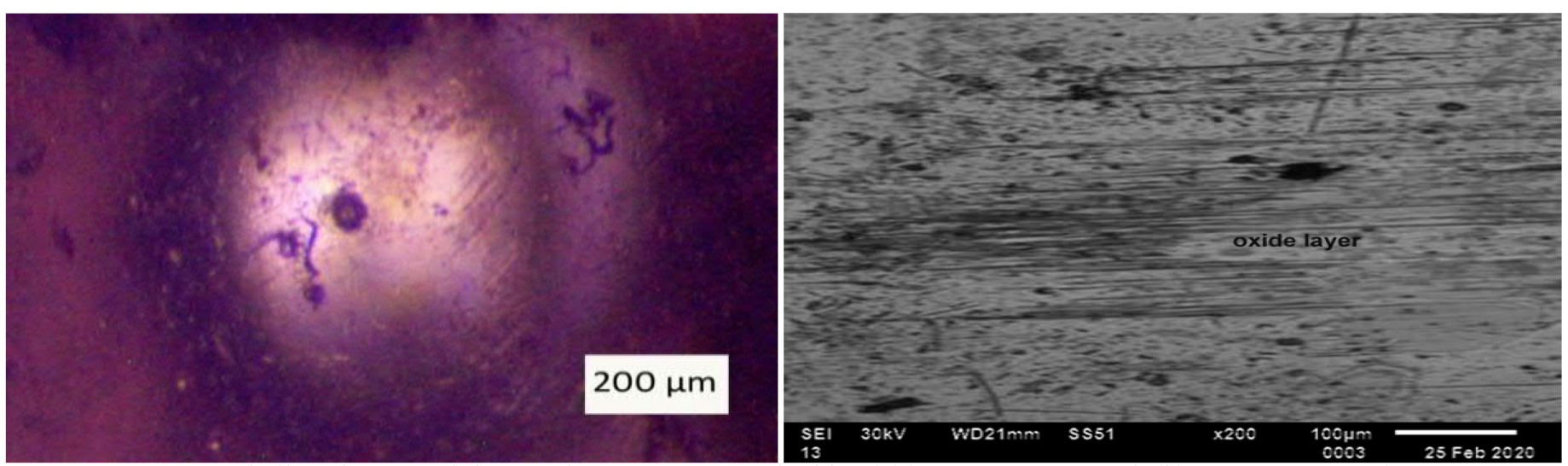

Fig. 25. AISI52100 ball under coated dry condition at $20 \mathrm{~N}$ applied load (a) AMM micrograph (b) SEM micrograph

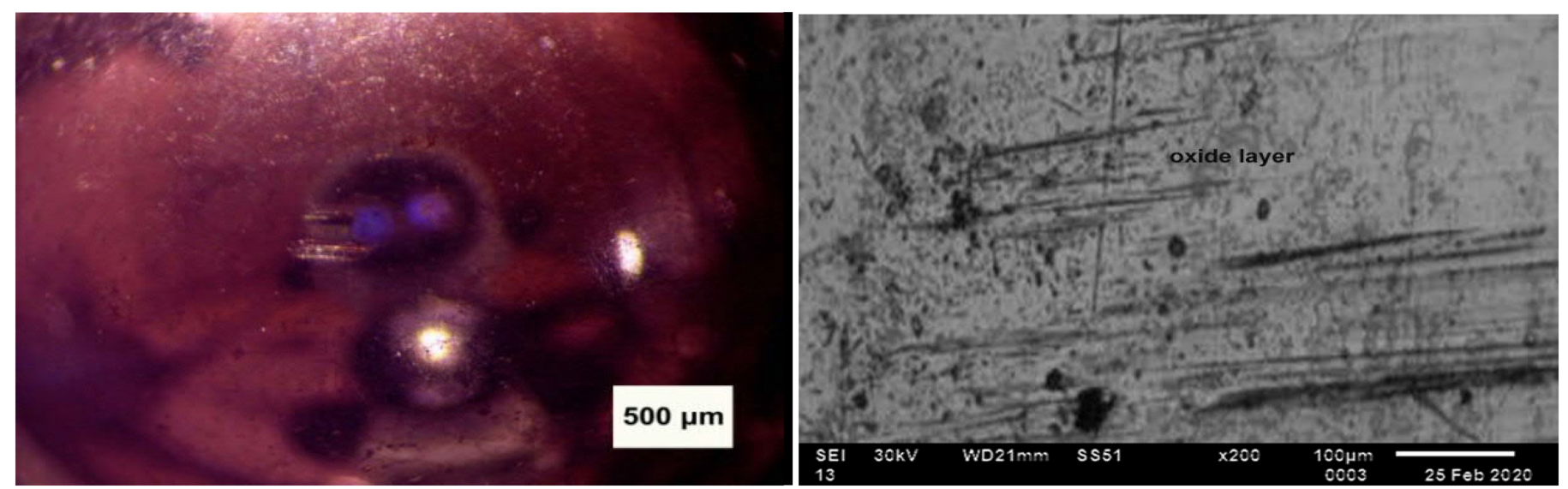

Fig. 26. AISI52100 ball under coated dry condition at $30 \mathrm{~N}$ applied load (a) AMM micrograph (b) SEM micrograph

DLC-Star coating for H-Al-17Si disc clearly showed through the optical, SEM, and profilometer micrographs. These results exhibit that DLC-Star coating possesses superior anti-friction and wear properties.

From the above results, it is clear that the DLC-Star coating comes up with a new pathway for enhancing the COF and wear characteristics that could be more carry out for many automobile sectors involving linear reciprocating sliding contact surfaces. However, DLC-Star coating is a modified diamond like carbon coating with improved load carrying capacity. An extraordinary hard, sturdy chromium nitride layer gives the required surface hardness and increases the load carrying capacity of the tribologically effective carbon coating. DLC-Star coating has even enhanced friction and wear performance than hydrogen free DLC coating. It is therefore used for the highest loaded components in diesel engine parts and injection systems.

\section{Conclusion}

In this investigation, we explored the effect of casting and coating on the tribological properties of H-Al-17Si MMC plate processed by rheo stir- squeeze casting method with different ( $5 \mathrm{~N}$ to $30 \mathrm{~N}$ ) loading under dry, lubricated and coated conditions.

The following conclusions were drawn from the experiments:

1. The friction coefficient for H-Al-17Si MMC against 


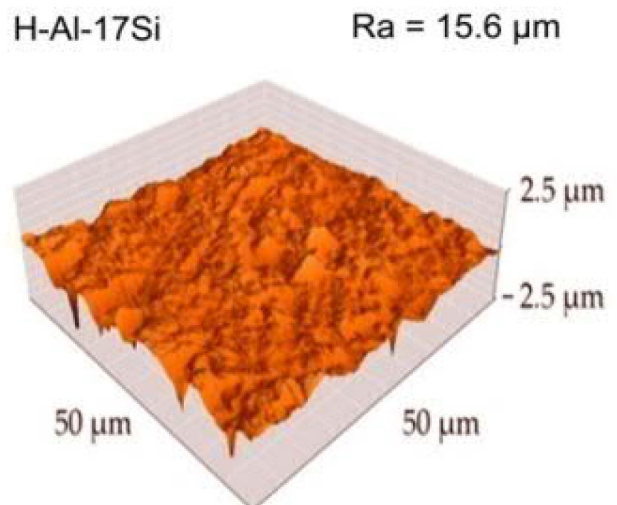

(a)

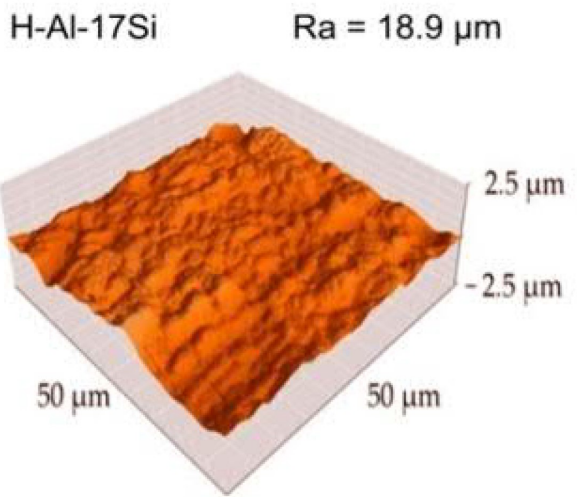

(b)

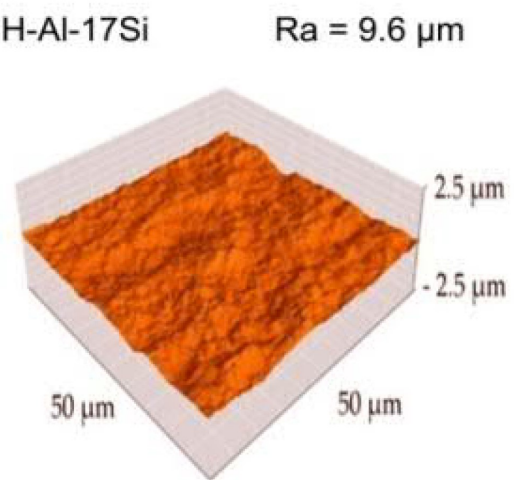

(c)

Fig. 27. Surface roughness micrographs of H-Al-17Si MMC under dry condition (a) $5 \mathrm{~N}$ (b) $20 \mathrm{~N}$ (c) $30 \mathrm{~N}$

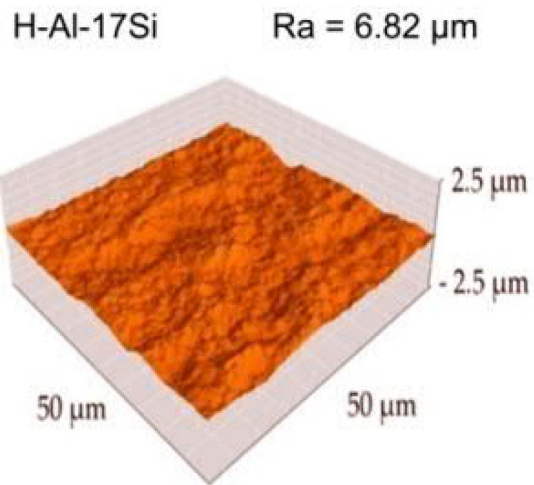

(a)

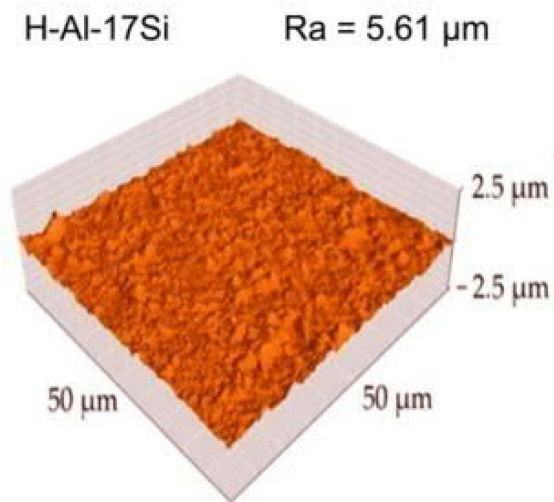

(b)

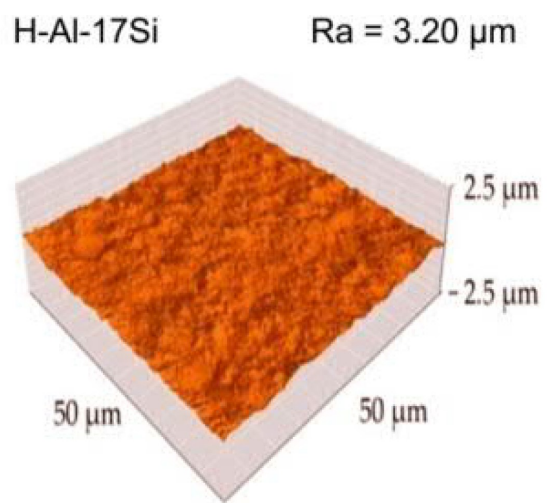

(c)

Fig. 28. Surface roughness micrographs of H-Al-17Si MMC under lubricated condition (a) $5 \mathrm{~N}$ (b) $20 \mathrm{~N}$ (c) $30 \mathrm{~N}$

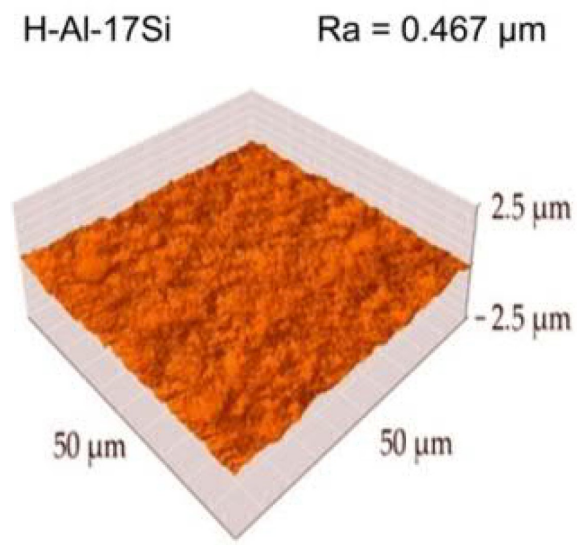

(a)

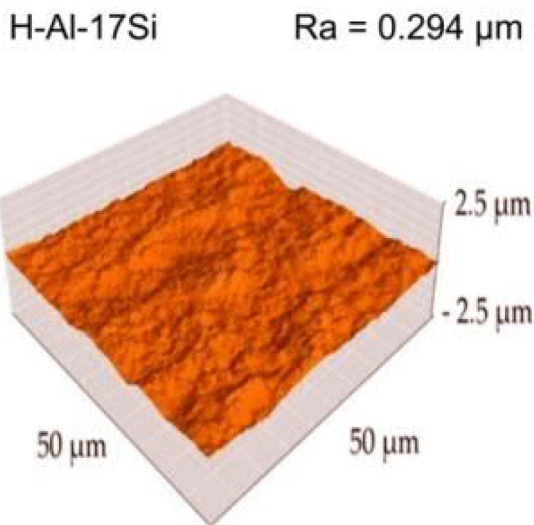

(b)

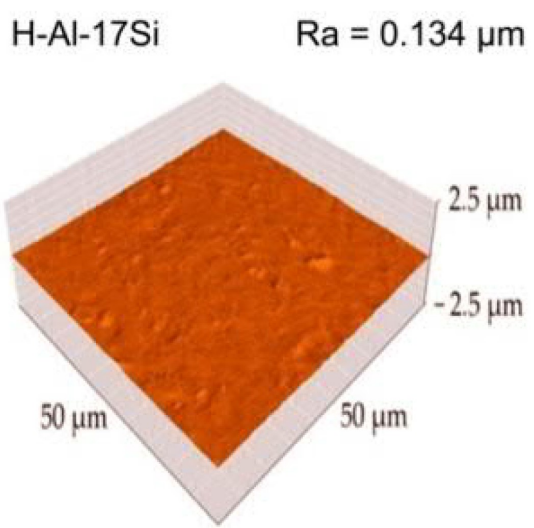

(c)

Fig. 29. Surface roughness micrographs of H-Al-17Si MMC coated dry condition (a) $5 \mathrm{~N}$ (b) $20 \mathrm{~N}$ (c) $30 \mathrm{~N}$

AISI52100 ball in dry sliding condition initially recorded a high value $(0.63)$ at $5 \mathrm{~N}$ then decrease with an increase in $(10 \mathrm{~N}$ to $30 \mathrm{~N})$ applied load. Though, in the condition of SAE15W40 engine oil and coated (DLC-Star) dry condition, the friction coefficient remarkably decreased with an increase in applied load.

2. Under dry condition the wear coefficients of H-Al17Si MMC increase with an increase in applied load and then decreases.

3. Significant reduction wear coefficients are adept with SAE15W40 engine oil at different loading conditions due to hard Si particles of the MMC performs as a solid lubricant in lubricated conditions.

4. Substantial effect on reduction of wear and friction coefficients were noticed in the case of H-Al-17Si MMC 
coated with $\mathrm{CrN}+$ a-c:H because of the development of a tribo oxidation film between tribo surfaces.

These solutions exhibit a passivation effect because of DLC-Star coating, which helped lower the wear coefficient between mating parts and supplied easy shearing and, therefore, resulted in friction improvement. Moreover, the results exhibit that DLC-Star coating possesses superior anti-friction and wear properties.

\section{Acknowledgment}

The DLC-Star $(\mathrm{CrN}+\mathrm{a}-\mathrm{c}: \mathrm{H})$ coating on H-Al-17Si was carried out at Oerlikon Balzers Coating India Private Limited with association with Excelanttechnologies, Hyderabad, India, under the coordination of Dinesh Rao .M.A and srinivas@excelanttechnologies.

\section{Nomenclature}

$\begin{array}{ll}\text { COF } & \text { Coefficient of friction } \\ \text { DLC } & \text { Diamond like carbon } \\ \text { RSSC } & \text { Rheo stir-squeeze casting } \\ \text { MMC } & \text { Metal matrix composite (alloy) } \\ \text { AFM } & \text { Atomic force microscope } \\ \text { H-Al-Si } & \text { Hyper-eutectic aluminum silicon } \\ \mathrm{Kw} & \text { Wear coefficient, } \mathrm{mm}^{3} / \mathrm{Nm} \\ \mathrm{Wv} & \text { Wear volume, } \mathrm{mm}^{3} \\ \mathrm{Sd} & \text { Sliding distance, } \mathrm{m} \\ \mathrm{Ra} & \text { Roughness average, } \mu \mathrm{m} \\ \mathrm{Fn} & \text { Load applied }(\mathrm{N})\end{array}$

\section{REFERENCES}

[1] S.D.A. Lawes, M.E. Fitzpatrick, S.V. Hainsworth, Evaluation of the tribological properties of DLC for engine applications, Journal of Physics D: Applied Physics, vol. 40, no. 18, pp. 5427-5437, 2007, https:// doi.org/10.1088/0022-3727/40/18/S03

[2] M.D. Sexton, T.E. Fischer, The Mild Wear of 52100 Steel, Wear, vol. 96, iss. 1, pp. 17-30, 1984, https:// doi.org/10.1016/0043-1648(84)90101-7

[3] J. Halling, New Directions in Lubrication, Materials, Wear and Surface Interactions- Tribology in the 80's, Surface engineering, vol. 1, iss. 4, pp. 243,1985 , https://doi.org/10.1179/sur.1985.1.4.243

[4] M.A. Islam, A.S.M.A. Haseeb, A.S.W. Kurny, Study of Wear of As-Cast and Heat-Treated Spheroidal Graphite Cast Iron Under Dry Sliding Conditions, Wear, vol. 188, iss. 1-2, pp. 61-65, 1995, https:// doi.org/10.1016/0043-1648(95)06605-5

[5] A.N. Farhanah, M.Z. Bahak, Engine oil wear resistance, Jurnal Tribologi, vol. 4, pp. 10- 20, 2015.

[6] M.F. Wani, A. Anand, Life-cycle assessment modelling and life-cycle assessment evaluation of a triboelement, Proceedings of the Institution of
Mechanical Engineers, Part J: Journal of Engineering Tribology, vol. 224, iss. 11, pp. 1209-1220, 2010, https://doi.org/10.1243/13506501JET747

[7] M.D. Sexton, T.E. Fischer, The mild wear of 52100 steel, Wear, vol. 96, iss. 1, pp. 17-30, 1984, https:// doi.org/10.1016/0043-1648(84)90101-7

[8] ASM Handbook, Friction, Lubrication, and Wear Technology, ASM International Handbook Committee, vol. 18, pp. 785, 1992.

[9] K. Mohammed Jasim, E.S. Dwarakadasa, Wear in AlSi Alloys under Dry Sliding Conditions, Wear, vol. 119, iss. 1, pp. 119-130, 1987, https:// doi.org/10.1016/0043-1648(87)90102-5

[10] P.K. Rohatgi, B.C. Pai, Effect of Microstructure and Mechanical Properties on the Seizure Resistance of Cast Aluminium Alloys, Wear, vol. 28, iss. 3, pp. 353 - 367, 1974, https:// doi.org/10.1016/0043-1648(74) $\underline{90192-6}$

[11] K.G. Kumar, Influence of Refinement and Modification on Dry Sliding Wear Behaviour of Hypereutectic Al-Si Cast Alloys, In Advanced Materials Research , vol. 685, pp. 112-116, 2013, https://doi.org/10.4028/www.scientific.net/ AMR.685.112

[12] Chong Lin, Shusen Wu, Shulin Lü, Ping An, Hebao $\mathrm{Wu}$, Effects of high pressure rheo-squeeze casting on Fe-containing intermetallic compounds and mechanical properties of Al-17Si-2Fe-(0, 0.8) V alloys, Materials Science and Engineering: A, vol. 713, pp. 105-111, 2018, https://doi.org/10.1016/ j.msea.2017.12.050

[13] R.G. Guan, Z.Y. Zhao, C.S. Lee, Q.S. Zhang, C.M. Liu, Effect of wavelike sloping plate rheocasting on microstructures of hypereutectic Al-18 pct Si-5 pct Fe alloys, Metallurgical and Materials Transactions B, vol. 43, pp. 337-343, 2012, https://doi.org/10.1007/ $\underline{\text { s11663-011-9592-4 }}$

[14] D. Pavlyuchkov, S. Balanetskyy, W. Kowalski, M. Surowiec, B. Grushko, Stable decagonal quasicrystals in the Al-Fe-Cr and Al-Fe-Mn alloy systems, Journal of Alloys and Compounds, vol. 477, iss. 1-2, pp. L41L44, 2009, https://doi.org/10.1016/ j.jallcom.2008.11.005

[15] Qiuping Wang, LuLi, Rongfeng Zhou, Fan Xiao, Baoyu Geng, Microstructures and wear behavior of the rheo-squeeze casting high silicon aluminium alloys pipe with the gradient structure, Materials Research Express, vol. 5, no. 10, pp. 106505, 2018, https://doi.org/10.1088/2053-1591/aad9cb

[16] Y.B. Zhang, J.C. Jie, Y. Gao, Y.P. Lu, T.J. Li, Effects of ultrasonic treatment on the formation of ironcontaining intermetallic compounds in Al-12\%Si-2\% Fe alloys, Intermetallics, vol. 42, pp. 120-125, 2013, 


\section{https://doi.org/10.1016/j.intermet.2013.05.018}

[17] Y. Osawa, S. Takamori, T. Kimura, M. Kazumi, K. Hideki, Morphology of intermetallic compounds in Al-Si-Fe alloy and its control by ultrasonic vibration, Materials Transactions, vol. 48, iss. 9, pp. 2467-2475, 2007, https://doi.org/10.2320/matertrans.FMRA2007874

[18] Vineet Tirth, S. Ray, M.I. Kapoor, Effect of Squeeze Pressure on Aging and Mechanical Properties of AA2218-5 Wt Pct Al2O3 (TiO2) Composites, Metallurgical and materials transactions A, vol. 40, pp. 1246-1254, 2009, https://doi.org/10.1007/s11661009-9815-3

[19] Vineet Tirth, Arabi Amir, Effect of liquid forging pressure on solubility and freezing coefficients of cast aluminum 2124, 2218 and 6063 alloys, Archives of Metallurgy and Materials, vol. 65, iss. 1, pp. 357-366, 2020, https://doi: 10.24425/amm.2020.131738

[20] A. Mahato, S. Xia, T. Perry, A. Sachdev, S.K. Biswas, Role of Silicon in Resisting Subsurface Plastic Deformation in Tribology of Aluminium-Silicon Alloys, Tribology International, vol. 43, iss. 1-2, pp. 381-387, 2010, https://doi.org/10.1016/ j.triboint.2009.06.020

[21] M. Warmuzek, Aluminum-Silicon Casting Alloys: An Atlas of Microfractographs, ASM international, vol. 9, pp. 39-44, 2004.

[22] Khemraj, A.K. Jha, S.N. Ojha, Tribo-mechanical behavior of complex hypereutectic Al-Si alloy compressed through a converging die at elevated temperatures, Materials Research Express, vol. 5, no. 7, pp. 6509, 2018, https:// doi.org/10.1088/2053$\underline{1591 / \text { aacc } 94}$

[23] S.K. Dey, T.A. Perry, A.T. Alpas, Micromechanisms of Low Load Wear in an Al-18.5\% Si Alloy, Wear, vol. 267, iss. 1, pp. 515-524, 2009, https:// doi.org/10.1016/j.wear.2008.11.011

[24] J. Clarke, A.D. Sarkar, Wear Characteristics of AsCast Binary Aluminum-Silicon Alloys, Wear, vol. 54, iss. 1, pp. 7-16, 1979, https://doi.org/10.1016/00431648(79)90044-9

[25] A.S. Reddy, B.P. Bai, K.S.S. Murthy, S.K. Biswas, Wear and Seizure of Binary Al-Si Alloys, Wear, vol. 171, iss. 1-2, pp. 115-127, 1994, https:// doi.org/10.1016/0043-1648(94)90354-9

[26] Parveen Kumar, M.F. Wani, Friction and wear characterization of hypereutectic Al-Si alloy/steel tribopair under dry and lubricated conditions, Jurnal Tribologi, vol. 15, pp. 21-49, 2017.

[27] Parveen kumar, M.F. Wani, Effect of load on the tribological properties of hypereutectic Al-Si alloy under boundary lubrication conditions, Material Research Express, vol. 4, iss. 11, pp. 6519, 2017,

\section{https://doi.org/10.1088/2053-1591/aa98e5}

[28] R. Greenberg, G. Halperin, I. Etsion, R. Tenne, The effect of $\mathrm{WS}_{2}$ nanoparticles on friction reduction in various lubrication regimes, Tribology Letters, vol. 17, pp. 179-186, 2004, https://doi.org/10.1023/ B:TRIL.0000032443.95697.1d

[29] L. Joly-Pottuz, F. Dassenoy, M. Belin, B. Vacher, J.M. Martin, N. Fleischer, Ultralow-friction and wear properties of IF-WS 2 under boundary lubrication, Tribology Letters, vol. 18, pp. 477-485, 2005, https:// doi.org/10.1007/s11249-005-3607-8

[30] L. Yadgarov, V. Petrone, R. Rosentsveig, Y. Feldman, R. Tenne, A. Senatore, Tribological studies of rhenium doped fullerene-like $\mathrm{MoS}_{2}$ nanoparticles in boundary, mixed and elasto-hydrodynamic lubrication conditions, Wear, vol. 297, iss. 1-2, pp. 1103-1110, 2013, https://doi.org/10.1016/j.wear.2012.11.084

[31] R. Rosentsveig, A. Gorodnev, N. Feuerstein, H. Friedman, A. Zak, N. Fleischer, J. Tannous, F. Dassenoy, R. Tenne, Fullerene-like $\mathrm{MoS}_{2}$ nanoparticles and their tribological behavior, Tribology Letters, vol. 36, pp. 175-182, 2009, https:/ / doi.org/10.1007/s11249-009-9472-0

[32] Q. Wan, Y. Jin, P. Sun, Y. Ding, Tribological Behaviour of a Lubricant Oil Containing Boron Nitride Nanoparticles, J. of Procedia Engineering, vol. 102, pp. 1038-1045, 2015, https:// doi.org/10.1016/ j.proeng.2015.01.226

[33] M.S. Charoo, M.F. Wani, Tribological properties of IF$\mathrm{MoS}_{2}$ nanoparticles as lubricant additive on cylinder liner and piston ring tribo-pair, Tribology in Industry, vol. 38, no. 2, pp. 156-162, 2016.

[34] M.S. Charoo, M.F. Wani, Tribological properties of h$\mathrm{BN}$ nanoparticles as lubricant additive on cylinder liner and piston ring, Lubrication Science, vol. 29, iss. 4, pp. 241-254, 2016, https://doi.org/10.1002/1s.1366

[35] C. Donnet, Recent progress on the tribology of doped diamond-like and carbon alloy coatings: a review, Surface and Coatings Technology, vol. 100-101, pp. 180-186, 1998, https://doi.org/10.1016/S0257-8972 (97)00611-7

[36] Grill. A, Diamond-like carbon: state of the art, Diamond and Related Materials, vol. 8, iss. 2-5, pp. 428-434, 1999, https://doi.org/10.1016/S0925-9635 (98)00262-3

[37] D. Sheeja, B.K. Tay, L.N. Nung, Feasibility of diamond-like carbon coatings for orthopaedic applications, Diamond and Related Materials, vol. 13, iss. 1, pp. 184-190, 2004, https://doi.org/10.1016/ j.diamond.2003.10.053

[38] Z.F. Zhou, K.Y. Li, I. Bello, C.S. Lee, S.T. Lee, Study of tribological performance of ECR-CVD diamond-like carbon coatings on steel substrates: Part 2 . The 
analysis of wear mechanism, Wear, vol. 258, iss. 10, pp. 1589-1599, 2005, https://doi.org/10.1016/ j.wear.2004.10.005

[39] H. Mohrbacher, B. Blanpain, J.P. Celis, J.R. Roos, Frictional Behaviour of Diamond-like carbon and diamond coatings in oscillating sliding, Surface Coating Technology, vol. 62, iss. 1-3, pp. 583-588, 1993, https:// doi.org/10.1016/0257-8972(93)90303-6

[40] B. Blanpain, H. Mohrbacher, J.P. Celis, J.R. Roos, Diamond Films Technology, vol. 3, pp. 177-188, 1994.

[41] H. Mohrbacher, J.P. Celis, Friction Mechanisms in Hydrogenated Amorphous Carbon Coatings, Diamond and Related Materials, vol. 4, iss. 11, pp. 1267-1270, 1995, https://doi.org/10.1016/0925-9635 (95)00306-1

[42] W. Ni, Y.T. Cheng, A.M. Weiner, T.A. Perry, Tribological behaviour of diamond-like-carbon (DLC) coatings against aluminium alloys at elevated temperatures, Surface and Coatings Technology, vol. 201, iss. 6, pp. 3229-3234, 2006, https:// doi.org/10.1016/j.surfcoat.2006.06.045

[43] S. Bhowmick, A.T. Alpas, The performance of hydrogenated and non-hydrogenated diamond-like carbon tool coatings during the dry drilling of 319 $\mathrm{Al}$, International Journal of Machine Tools and Manufacture, vol. 48, iss. 7-8, pp. 802-814, 2008, https://doi.org/10.1016/j.ijmachtools.2007.12.006

[44] S. Bhowmick, M.J. Lukitsch, A.T. Alpas, Tapping of Al-Si alloys with diamond-like carbon coated tools and minimum quantity lubrication, Journal of Materials Processing Technology, vol. 210, iss. 15, pp. 2142-2153, 2010, https://doi.org/10.1016/ j.jmatprotec.2010.07.032

[45] S. Bhowmick, A.T. Alpas, Minimum quantity lubrication drilling of aluminium-silicon alloys in water using diamond-like carbon coated drills, International Journal of Machine Tools and Manufacture, vol. 48, iss. 12-13, pp. 1429-1443, 2008, https:// doi.org/10.1016/j.ijmachtools.2008.04.010

[46] S. Bhowmick, A.T. Alpas, The role of diamond-like carbon coated drills on minimum quantity lubrication drilling of magnesium alloys, Surface and Coatings Technology, vol. 205, iss. 23-24, pp. 5302-5311, 2011, https:// doi.org/10.1016/ j.surfcoat.2011.05.037

[47] A. Erdemir, C. Donnet, Tribology of diamond-like carbon films: Recent progress and future prospects, Journal of Physics D: Applied Physics, vol. 39, no. 18, pp. R311-R327, 2006, https:// doi.org/10.1088/00223727/39/18/R01

[48] A. Erdemir, O.L. Eryilmaz, G.R. Fenske, Synthesis of diamond like carbon films with superlow friction and wear properties, Journal of Vacuum Science \&
Technology A, vol. 18, iss. 4, pp. 1987-1992, 2000, https://doi.org/10.1116/1.582459

[49] A. Erdemir, O.L. Eryilmaz, I.B. Nilufer, G.R. Fenske, Effect of source gas chemistry on tribological performance of diamond-like carbon films, Diamond and Related Materials, vol. 9, iss. 3-6, pp. 632-637, 2000, https://doi.org/10.1016/S0925-9635(99)003611

[50] A. Erdemir, O.L. Eryilmaz, I.B. Nilufer, G.R. Fenske, Synthesis of superlow friction carbon films from highly hydrogenated methane plasmas, Surface Coating Technology, vol. 133-134, pp. 448-454, 2000, https://doi.org/10.1016/S0257-8972(00)00968-3

[51] J.R. Davis, Friction and wear of internal combustion engine parts, in ASM Handbook, Friction, Lubrication, and Wear Technology, ASM International, Materials Park, $\mathrm{OH}$, vol. 18, no. 10, pp. 553-562, 1992.

[52] W.S. Miller, L. Zhuang, J. Bottema, A.J. Wittebrood, P. De Smet, A. Haszler, A. Vieregge, Recent development in aluminium alloys for the automotive industry, Materials Science Engineering: A, vol. 280, iss. 1, pp. 37-49, 2000, https://doi.org/10.1016/ $\underline{\text { S0921-5093(99)00653-X }}$

[53] J.E. Hatch, Aluminium: Properties and Physical Metallurgy, ASM, Metals Park, OH, pp. 231-32, 1984.

[54] H. Torabian, J.P. Pathak, S.N. Tiwari, Wear Characteristics of Al-Si Alloys, Wear, vol. 172, iss. 1, pp. 49-58, 1994, https:// doi.org/10.1016/0043-648 (94)90298-4

[55] C.M. Chen, C.C. Yang, C.G. Chao, Dry Sliding Wear Behaviours of Al-25Si-2.5 Cu-1Mg Alloys Prepared by Powder Thixocasting, Materials Science and Engineering: A, vol. 397, iss. 1, pp. 178-189, 2005, https://doi.org/10.1016/j.msea.2005.02.010

[56] N.D. Malleswararao.K, Dr. I.N. Niranjan kumar, Mechanical Characterization of Rapid Solidified Alsicumg Alloys by New CRSS Casting Method Under T6 Condition, International Journal of Innovative Technology and Exploring Engineering (IJITEE), vol. 8, iss. 12, pp. 2897-2902, 2019, https:// doi: 10.35940/ijitee.K1577.1081219

[57] N. Saheb, T. Laoui, A.R. Daud, M. Harun, S. Radiman, R. Yahaya, Influence of Ti Addition on Wear Properties of Al-Si Eutectic Alloys, Wear, vol. 249 , iss. 8 , pp. $656-662,2001$, https:// doi.org/10.1016/S0043-1648(01)00687-1

[58] E. Konca, Y.T. Cheng, A.M. Weiner, J.M. Dasch, A. Erdemir, A.T. Alpas, Transfer of $319 \mathrm{Al}$ alloy to titanium diboride and titanium nitride based (TiAlN, TiCN, TiN) coatings: effects of sliding speed, temperature and environment, Surface and Coatings Technology, vol. 200, iss. 7, pp. 2260-2270, 2005, 
https:// doi.org/10.1016/j.surfcoat.2004.10.008

[59] K. Saijo, M. Yagi, K. Shibuki, S. Takatsu, The improvement of the adhesion strength of diamond films, Surface and Coatings Technology, vol. 43-44, pp. 30-40, 1990, https://doi.org/10.1016/0257-8972 (90)90057-I 